\title{
Data-driven streamflow modelling in ungauged basins: regionalizing random forest $(\mathrm{RF})$ models
}

\author{
Arnan Araza ${ }^{1,2}$, Lars Hein ${ }^{1}$, Confidence Duku ${ }^{1}$, Maurice Andres Rawlins ${ }^{3 *}$, \\ and Richard Lomboy ${ }^{4}$ \\ ${ }^{1}$ Wageningen University and Research - Environmental Systems Analysis, Environmental Sciences Group, \\ Droevendaalsesteeg 3 6708PB Wageningen, Netherlands \\ ${ }^{2}$ Wageningen University and Research - Laboratory of Geo-information and Remote Sensing, \\ Environmental Sciences Group, Droevendaalsesteeg 3 6708PB Wageningen, Netherlands \\ ${ }^{3}$ Natural Resources Management, The World Bank Group, Landover, MD 20785, United States \\ ${ }^{4}$ Department of Public Works and Highways - Water Designs Division, Philippines, Bonifacio Drive Port
} Area, Metro Manila, Philippines

\section{Key Points:}

- Ungauged sub-basins (watersheds) can effectively use RF streamflow models from gauged watersheds if both belong to the same cluster.

- Biophysical data from high-resolution open data are valuable: as basis for watershed clustering and as streamflow predictors to RF models.

- The predicted streamflow from the RF models reflects seasonal deviations in streamflow caused by natural and man-made water regulation

\footnotetext{
*Disclaimer: The views expressed in this article do not reflect the position or opinions of The World Bank Group.

Corresponding author: Arnan Araza, arnanaraza2006@gmail.com
} 


\begin{abstract}
Streamflow predictions in ungauged basins (PUB) has been geared towards data-driven methods, including the use of machine learning methods such as random forest (RF). Such methods are applied in PUB regionalization or the transfer of a streamflow model from gauged to ungauged (sub) basins or watersheds after grouping watersheds on similarity rules. Regionalized streamflow models are needed for tropical-mountainous regions like Luzon, Philippines - where gauged data is limited - but demands on streamflow modelling for water resources accounting and management are high. In 21 watersheds in Luzon, we "regionalize" RF streamflow models after grouping watersheds based on: a principal components analysis (PCA-clustered), by major river basins (basin-clustered), whole study area scale (one-clustered). Another method without watershed grouping (watershed-level) was also included and inter-compared. Among the four methods, goodness-of-fit evaluations revealed that PCA-clustered method was higher by at most 0.35 coefficient of determination $R^{2}$ and 0.31 nash-sutcliffe efficiency $N S E$, and the least bias in 8 of 12 monthly flows. These are attributed to the addedvalue of homogeneous watershed grouping, reflected by higher importance (to RF models), of static covariates from open and high-resolution data. Normalized errors from monthly streamflow showed a clear bias (least with the PCA-clustered metohd), linked to season and water management practices in the study area. Ungauged watersheds in the Philippines can effectively use streamflow models from gauged watersheds if they belong to the same cluster.
\end{abstract}

Keywords: Streamflow, PUB, Random Forest, Data-driven, Watershed clustering, Regionalization 


\section{Introduction}

Globally, water resources are increasingly under pressure from over-exploitation, deforestation affecting streamflow patterns, and climate change (Oki, 2006). Better managing river water resources requires detailed information on streamflow and how streamflow depends upon river basin management. However, in many tropical and developing countries, in-situ streamflow monitoring networks are neither adequately maintained nor have sufficient spatial coverage in the river basins (Do et al., 2018). This is also the case in the Philippines where streamflow data scarcity and paucity have hampered credible streamflow estimates for major river basin management (Tuddao Jr, 2009).

Streamflow prediction in ungauged and poorly gauged basins (PUB) is commonly performed using hydrological model-based approaches (Hrachowitz et al., 2013). These include process-based methods which depend on physics-based natural processes. Process-based methods are parametric, which make use of model and inputspecific parameters to perform a water balance simulation using empirical equations (Arnold et al., 2012). Process-based models are often implemented in user interfaces, enabling input-level modifications to model not only business as usual events, but also land-use change, climate change, drought, and land management scenarios in subbasins (herein referred as watersheds) scales (Jaranilla-Sanchez et al., 2011; Mango et al., 2011; Palao et al., 2013). For large scale-applications, e.g. in multiple states (Mohamoud, 2008) or at pan-European scale (Pagliero et al., 2019), watershed regionalization is often applied first before executing a hydrologic model. Regionalization includes transferring hydrological model and(or) model parameters from gauged watersheds to ungauged ones in a "donor-receiver" logic. Transfer is either based on watershed-to-watershed distance (like spatial proximity) or based on regression of hydrological parameters and watershed characteristics (Beck et al., 2016). A review by Razavi \& Coulibaly (2013) identified at least 30 unique regionalization studies conducted in the past decades mostly for engineering applications. On the other hand, they also categorized PUB as hydrological model-independent or a non-parametric approach that bypasses hydrological models and its parameters. In this case, the watershed characteristics functioning as explanatory variables of a gauged watershed are calibrated directly with streamflow itself to create a "streamflow model" usable to ungauged watersheds. This empirical method has emerged as an alternative to model-dependent methods for practical reasons of non-parameterization and faster implementation (Loukas \& Vasiliades, 2014). Moreover, conducive to this approach is the advent of input-level big data, redefining model-independent as data-driven methods (Razavi \& Coulibaly, 2013). Contextually, a data-driven method is defined as the empirical and non-physics-based calculations in river basins using considerable amount of data and machine learning (Solomatine \& Ostfeld, 2008).

The broad state-of-the-art application of machine learning (ML) in water resources modelling has been categorized to forecasting, preprocessing, variable selection, training-testing dataset optimization, and predictive performance assessments (Tyralis et al., 2019). One of the most used ML methods in water resources is Random Forest (RF), a supervised algorithm for predictive modelling developed by (Breiman, 2001). 
Currently, $\mathrm{RF}$ is widely-used in solving regression-based problems and is perceived to solve more complex water resources problems in the future (Tyralis et al., 2019). When applied to streamflow modelling, comparatively, RF has shown more optimal streamflow predictions (Papacharalampous \& Tyralis, 2018) and slightly better streamflow model accuracy (Shortridge et al., 2016) than other ML methods. But what makes $\mathrm{RF}$ unique, aside from its predictive power and efficiency in non-linear relationships, is the capability to provide importance values to explanatory variables (Tyralis et al., 2019). For example, Bruner et al., (2018) showed that physical watershed parameters explain most of the RF streamflow model variability to predict flood hydrographs and (Shortridge et al., 2016) highlighted the sensitivity of streamflow models to temperature as proxy to climate change effects. Furthermore, uncertainties in RF model predictions are quantifiable (Wager et al., 2014). But in watershed regionalization, $\mathrm{RF}$ and so with other ML methods, are mostly used only as a complementing model in regionalizing parameters of hydrological models (Saadi et al., 2019; Brunner et al., 2018; Senent-Aparicio et al., 2019), large-scale but non-regionalized streamflow modelling (Asefa et al., 2006), and watershed classification or grouping (Yadav et al., 2007; Isik \& Singh, 2008).

Pivotal to the success of regionalization is on how well watersheds are grouped or classified. While the choice of grouping method is subjective to basin characteristics and study area scale (Saadi et al., 2019), "homogeneous" classification of watersheds at regional-scale has been widely-tested. In similar studies, almost all of regional variability was captured when datasets are transformed into principal components, thus becoming the watershed grouping basis (Isik \& Singh, 2008; Prieto et al., 2019). Such method was found effective to perform adequacy evaluation of streamflow models. In less heterogeneous regions, grouping neighboring watersheds together (e.g. inside a major river basin) is reasonable (Oudin et al., 2008). Effective grouping could facilitate the use of RF streamflow model itself to be "regionalized" in ungauged watersheds. For example, one performed watershed clustering and streamflow modelling to better predict monthly streamflow (Wu et al., 2010) while another did the same to predict flood indices (Latt et al., 2014). These examples both evaluated their models only at cluster level, and not at watershed-level e.g. by using pseudo-ungauged watersheds (Goswami et al., 2007; Athira et al., 2015). Moreover, streamflow models should be evaluated whether predicted streamflow shows systematic deviations (e.g. seasonal) or bias, but they are often disregarded (Arsenault \& Brissette, 2014). Other similar studies confined regionalization of RF models at basin scales and none has attempted in tropical-mountainous regions.

Tropical-mountainous regions often have complex hydrological system with various natural and human-induced impacts on hydrological interactions (Wohl et al., 2012). Moreover, these regions have very limited streamflow data, but high streamflow modelling demands on water resources research and development (R\&D) for better watershed management. Given these, the main objective of this paper is to test and compare how a regionalized, RF-based streamflow models can be used to predict streamflow in ungauged watersheds in mountainous regions of Luzon, Philippines. In line with that goal are the following research questions: (1) What is the effect of wa- 
tershed grouping in regionalizing RF models? (2) How are open and high-resolution data useful in RF model regionalization? and (3) What influences seasonal bias in streamflow predictions?

\section{Study area}

Our study area includes 21 watersheds within six major river basins and covers five administrative regions in Luzon, Philippines. The study area is shown in Figure 1 where each watershed is labeled according to its respective major river basin and the river or station name e.g. crb_a is equivalent to Cagayan River Basin, Aligapay River.

Inside the study area are the top crop producing provinces of the country. This means that long-term water management for irrigation is very important to sustain crop production. The water for irrigation comes from the headwaters of Sierra Madre and Cordillera mountains - two of largest mountain ranges in the country. With mountain ridges up to 2000 meters high, the watersheds depict a ridge-to-floodplain form of irregular and elongated sizes ranging from 20 to $10,000 \mathrm{~km}^{2}$. This shape and size allow a sloping terrain topography with mostly mountain, silt, and clay soils. The forests in these area sustain river flows even in driest months of March and April. More than half of these forests $(60 \%)$ are classified as public forest lands. The forests contribute to make more rain up to around $2000 \mathrm{~mm} /$ year in most of the watersheds. In wet season, the lowland of the study area is a floodplain with high risks of flooding and landslide due to typhoons (Cinco et al., 2018). These impacts are aggravated by deforestation and climate change (Rawlins et al., 2016). As a response, the government formulated management plans in every major river basin focusing on long-term domestic water use, modernizing irrigation, and flood mitigation.

\section{Methods}

This study implements three stages to regionalize RF models into ungauged watersheds (Figure 2). The steps are elaborated in the succeeding sub-sections. As an overview, section 3.1 is about the open and high resolution data inputs turned streamflow predictors or covariates. Section 3.2 tackles the two-step nature of regionalization: watershed grouping and RF streamflow model "transfer". Lastly, in section 3.3, predicted streamflow are evaluated relative to uncertainties from RF models and seasonal bias.

\subsection{Input data and covariates}

The basis of input data selection is to represent the main components of a tropical mountainous hydrological system including streamflow, biophysical, climatic, and other complementary data. Another basis is the ease of access from these data.

We obtained 51,690 records of daily streamflow data (herein referred as observed streamflow), ranging from 2000 to 2016, and expressed as $\mathrm{m}^{3} / \mathrm{s}$. The observed data come from 21 gauged stations and computed by averaging three daily gauge measurement. Geo-tagging the stations allowed us to delineate 21 watersheds from an elevation raster using ArcHydro tool (Maidment \& Morehouse, 2002). Within and nearby these 


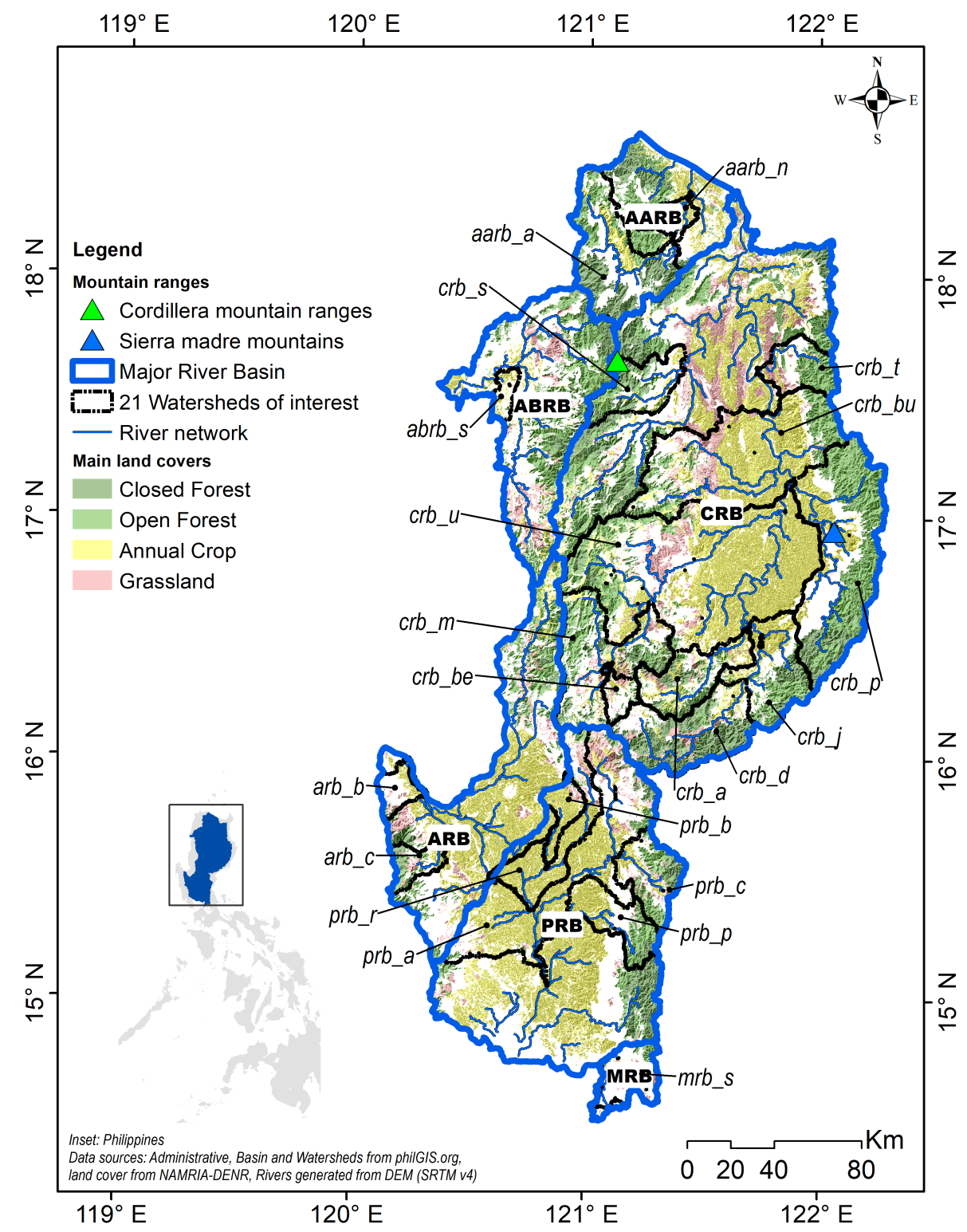

Figure 1. Study area overview showing the 21 watersheds within the 6 major river basins in Luzon namely Abra, Agno, Apayao-Abulog, Cagayan, Marikina, and Pampanga River Basins. The basins are labelled as $a b r b$, arb, aarb, $c r b, m r b$, and $p r b$, respectively. River networks are shown also to guide upstream-downstream connections within watersheds while main land covers show how forested the uplands and cultivated the lowlands are. 


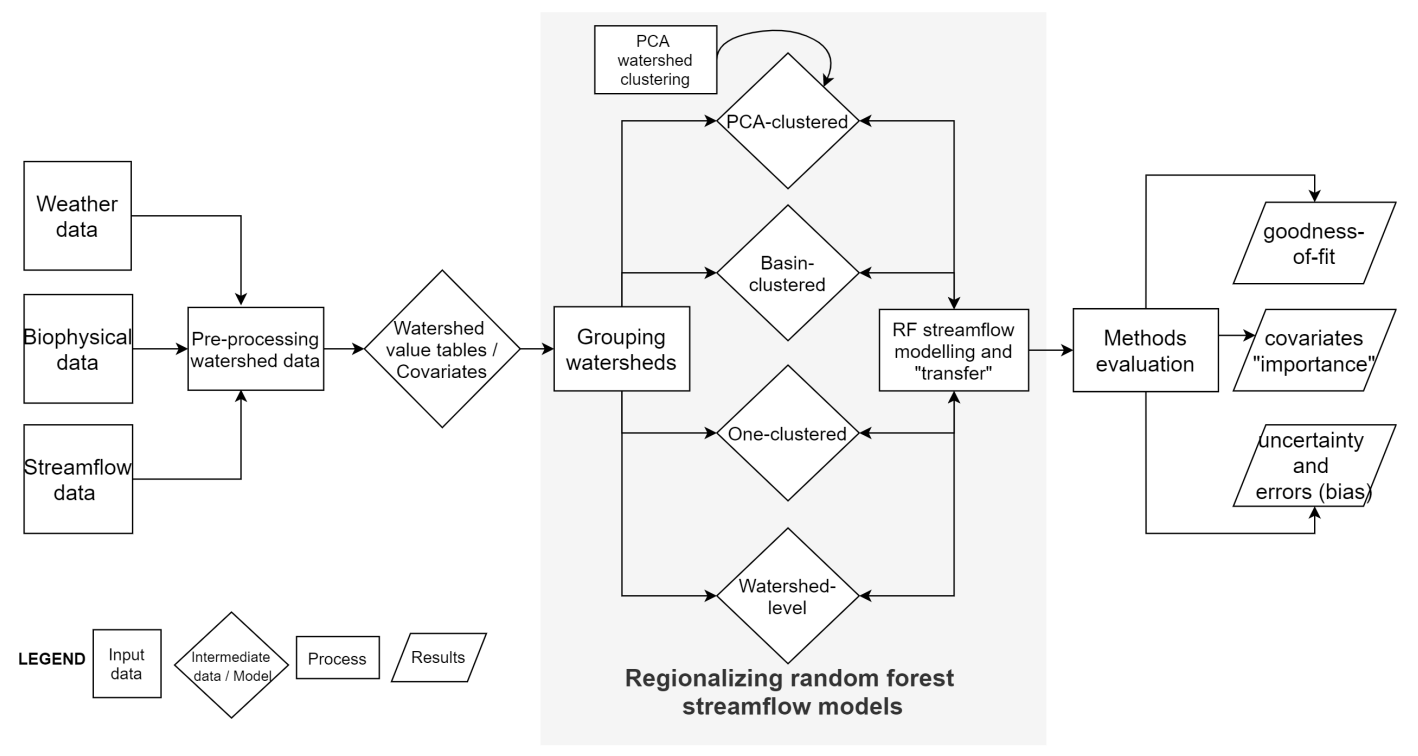

Figure 2. Overall diagram of the steps undertaken in this study starting from data collation, regionalization of $\mathrm{RF}$ models, and ending with models evaluation.

watersheds, we obtained weather data from local monitoring stations. The gaps in daily weather data were interpolated using predictions from a linear regression model of the "gap station" and neighboring weather station. Vegetation inputs were represented by land cover data from 30m Global Land Cover (Arsanjani et al., 2016) and forest-loss from 30m Global Forest Change (Hansen et al., 2013). The latter was included to depict the forest loss history in the area. Soil inputs came from a global but high resolution soil dataset raster $(250 \mathrm{~m})$ from World Soil Information (Hengl et al., 2017). The dataset is a collection of model-based predictions using soil profile and environmental variables. Next, elevation was included to capture the ridge-to-floodplain form of the watersheds. For that, we used the 30m Shuttle Radar Thematic Mapper Digital Elevation Model Version 4 (SRTM-DEM V.4) (Jarvis et al., 2008), which has higher resolution and vertical accuracy than other similar options (Pryde et al., 2007). From the elevation data, slope was derived as the last main input. All rasters were projected into UTM Zone $51 \mathrm{~N}$ then mosaicked and masked within the study area using Geospatial Abstraction Library (Warmerdam, 2008). After that, coarser rasters were resampled into $30 \mathrm{~m}$ using nearest neighbor approach to match spatial resolutions. To better represent soil, elevation, and slope instead of using the mean, we reclassified them into five classes. We classified the rasters by quantiles to assure equal population within classes (with 5 as the highest value). As complementary watershed data, we included climate type, month, land area, and the major river basin where it belongs. The final pre-processing step was to overlay all inputs per watershed. All data pre-processing were implemented in $R$ (R Core Team, 2013) in $R$ studio.

All non-streamflow input data were used as covariates, also known as explanatory variables or predictors. From the main inputs, more covariates were derived and 
Table 1. List and key information of main covariates including the main data inputs, number of covariates derived from main inputs, covariates labels, measuring unit, and temporal unit. Each watershed has an equivalent value table.

\begin{tabular}{|c|c|c|c|c|c|}
\hline No. & Main input & Covariates (number) & Labels & Unit & Temporal unit \\
\hline 1 & $\begin{array}{l}\text { Rainfall (daily, weekly, } \\
\text { monthly, max) }\end{array}$ & 4 & $\begin{array}{c}\text { W.pcp, W.pcpw, } \\
\text { W.pcpm, W.pcpmx }\end{array}$ & $\mathrm{mm}$ & dynamic \\
\hline 2 & $\begin{array}{l}\text { Daily Temperature } \\
\quad(\min , \max )\end{array}$ & 1 & W.tmin, W.tmax & $\mathrm{C}^{\circ}$ & dynamic \\
\hline 3 & Daily Wind Speed & 1 & W.ws & $\mathrm{m} / \mathrm{s}$ & dynamic \\
\hline 4 & $\begin{array}{l}\text { Daily Relative } \\
\text { Humidity }\end{array}$ & 1 & W.rh & $\%$ & dynamic \\
\hline 5 & Bulk Density & 5 & P.bd1-P.bd5 & hectare (ha) & static \\
\hline 6 & Sandy soil & 5 & P.sa1-P.sa5 & ha & static \\
\hline 7 & Silty soil & 5 & P.si1-P.sa5 & ha & static \\
\hline 8 & Clayish soil & 5 & P.cl1-P.cl5 & ha & static \\
\hline 9 & Soil depth & 5 & P.sd1-P.sd5 & ha & static \\
\hline 10 & Curve Number & 1 & H.cn & unitless coefficient (0-1) & dynamic \\
\hline 11 & Manning's Roughness & 1 & H.m & unitless coefficient $(0-1)$ & dynamic \\
\hline 12 & Net annual forest loss & 1 & H.fl & ha & dynamic \\
\hline 13 & $\begin{array}{l}\text { Land covers (grass, } \\
\text { river, barren, forest, } \\
\text { agriculture, built-up, } \\
\text { shrubs, wetland) }\end{array}$ & 6 & $\begin{array}{l}\text { L.gr, L.riv, L.bar, } \\
\text { L.for, L.agr, L.bu, } \\
\text { L.shr, L.wet }\end{array}$ & ha & static \\
\hline 14 & DEM & 5 & P.dem1-P.dem5 & $\mathrm{m}$ & static \\
\hline 15 & Slope & 5 & P.sl1-P.sl5 & \%rise & static \\
\hline 16 & Absolute area & 1 & C.area & ha & static \\
\hline 17 & Basin name & 1 & C.basin & categorical (1-6) & static \\
\hline 18 & Climate type & 1 & S.clim & categorical (1-4) & dynamic \\
\hline 19 & Month & 1 & S.mo & categorical (1-12) & dynamic \\
\hline
\end{tabular}

categorized as weather $(\mathrm{W})$, physical $(\mathrm{P})$, land cover $(\mathrm{L})$, hydrologic $(\mathrm{H})$, season $(\mathrm{S})$ and complement $(\mathrm{C})$. Based on daily rainfall data, weekly and monthly rainfall were derived to capture short-term and seasonal rainfall patterns. From the land cover, each land cover class was a separate covariate; and so were hydrologic parameters curve number and Manning's roughness - these two are unique per land cover class. Similarly, each class from soil, slope, and elevation inputs was a stand-alone covariate. In total, 55 covariates were generated as shown in Table 1, where each main input has covariates count, label, measuring unit, and temporal unit. The labelling is intended not only for concise naming of covariates (e.g. for results), but also to emphasize the covariates category. The covariates are also categorized whether static or dynamic to assess how streamflow models are affected by temporal variations. Temporally, the covariates are balanced in number: weather covariates are the most dynamic with daily to monthly values, while the hydrologic covariates are yearly. A land cover class could be dynamic if forest conversion happens because of annual net forest loss. The climate and physical covariates are static for a reason since soil, slope, and elevation gradually change.

These covariates constitute the watershed information and were merged into a collated table we refer to as watershed value table. This table is unique per watershed and served as the formatted data for streamflow model training and evaluation using random forest. 


\subsection{Regionalizing random forests}

As mentioned, RF has been widely applied into water resources research and development towards solving non-linear problems in hydrology through data-driven methods. That is in line with our expectations that RF can capture streamflow responses in a 16-year stretch that will allow RF streamflow models usable to ungauged watersheds. All that watershed information are placed in each watershed value table as input for regionalization.

\subsubsection{RF algorithm}

Random forest algorithm by (Breiman, 2001) is a supervised learning model used for classification and regression. We used it for the latter because streamflow is a continuous variable. Conceptually, the algorithm works in five steps as demonstrated in Figure 3 in a single RF tree. First, a watershed value table is assembled, where observed streamflow and the covariates are placed in columns. Second, the watershed value table undergoes bootstrapping, where the rows are randomly selected (with replication) to form a sub-sample or simply a bootstrap sample of the watershed value table. Third, from this random subset, the root node (topmost circle of a tree, Figure 3 ) is randomly selected from a limited choices of covariates. The root node is split based on a yes-no decision - leading into two succeeding nodes - again coming from a limited set of covariates. Fourth, nodes increase (bagging or "tree growing") on every binary decision until reaching the final decision. That bagging step de-correlates the covariates within the tree and assuring lesser prediction variance. That distinguishes RF from the unrestricted splitting of the traditional bagging method. Lastly, as trees grow in parallel, the final decision of each tree are averaged to get the final predicted streamflow. RF prediction can be written as:

$$
\hat{\theta}^{R F}(Q)=\frac{1}{T} \sum_{b=1}^{T} \operatorname{pred}_{t}^{*}\left(Q ; \operatorname{Cov}_{t 1}^{*}, \ldots, \operatorname{Cov}_{t n}^{*}\right)
$$

where streamflow is predicted pred $_{t}^{*}$ from an individual tree of an RF streamflow model $\hat{\theta}^{R F}(Q)$ as the average prediction among the decision trees 1 to $B$ with covariates $\operatorname{Cov}_{t 1}^{*}$ to $\operatorname{Cov}_{t n}^{*}$.

We used the $\mathrm{RF}$ algorithm using the ranger package in $\mathrm{R}$ for faster implementation (Wright \& Ziegler, 2017). Prior to that, the RF hyperparameters were tuned to an optimal value. These parameters are: (1) the limited choices of covariates when trees grow (recall step 3, Figure 3), also called as the "split variable"; (2) another is the maximum number of bootstrap samples or trees to grow ("number of trees") in a random forest. The two hyperparameters are termed as mtry and num.trees in ranger package). The correct value of the two considers the trade-off between overfitting and computation time. If the split variable is set too high, the model could overfit or see repetitive information, and produce highly correlated trees (Probst et al., 2019). Most likely, that will inaccurately predict streamflow from any new dataset. After the tun- 


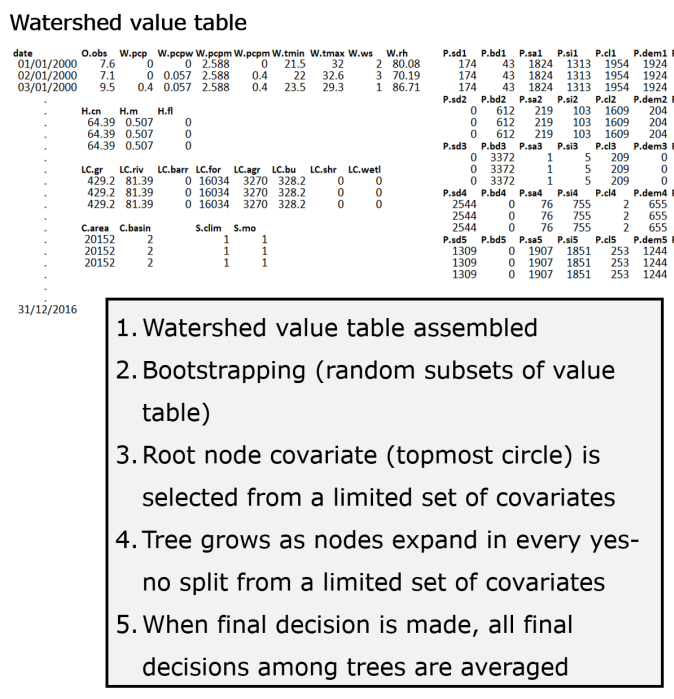

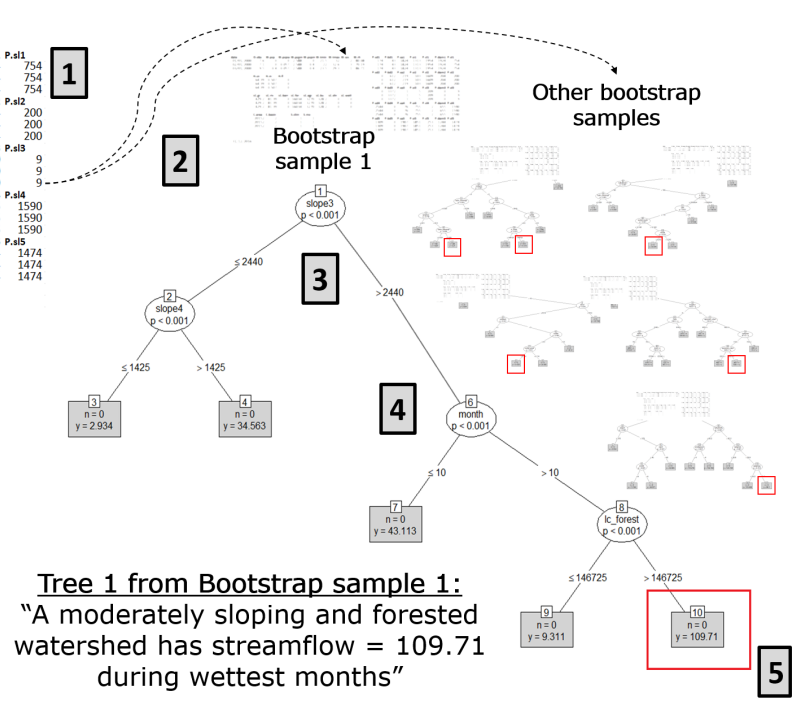

Figure 3. Summary of RF implementation highlighting one tree from a bootstrapped sample, to (restricted) tree growing, until the final predictions in red boxes. The quoted line in the diagram depicts the link of the predicted streamflow all throughout the root (topmost) node.

ing, the split variable was set to be $1 / 4$ of the total covariates while the default value of the number of trees (500) was retained.

\subsubsection{Regionalization methods}

We define the term "regionalization" as the transfer of streamflow models from gauged to ungauged watersheds after a watershed grouping scheme based on similarity rules. The "grouping" not only assigns watersheds into groups, but also their information or watershed value tables for a certain RF model training. With this twostep approach, we trained RF models depending whether the watershed grouping is PCA-clustered, basin-clustered, and all-clustered. We also included a method without watershed grouping. These methods are depicted in Figure 4.

The first method uses principal components analysis (PCA) to cluster watersheds into four, resulting to an RF model per cluster (elaborated next section). The second method assigns the watersheds to their mother river basin resulting to six RF models corresponding to each major river basin. This grouping method can signal whether basin-level variability is evident. The third method merges all watershed value table to train one RF model. In this case, we assessed if the RF model can still predict accurately from a training data with all watershed information at the whole study area scale (Luzon). Lastly, there was no watershed value table grouping, giving one RF model per watershed or simply no regionalization. Watershed-level streamflow modelling is very common in poorly gauged watersheds using process-based methods and these watersheds are partly categorized as PUB (Loukas \& Vasiliades, 2014). We wanted to check how streamflow data gaps can be compensated with and without regionalization. 


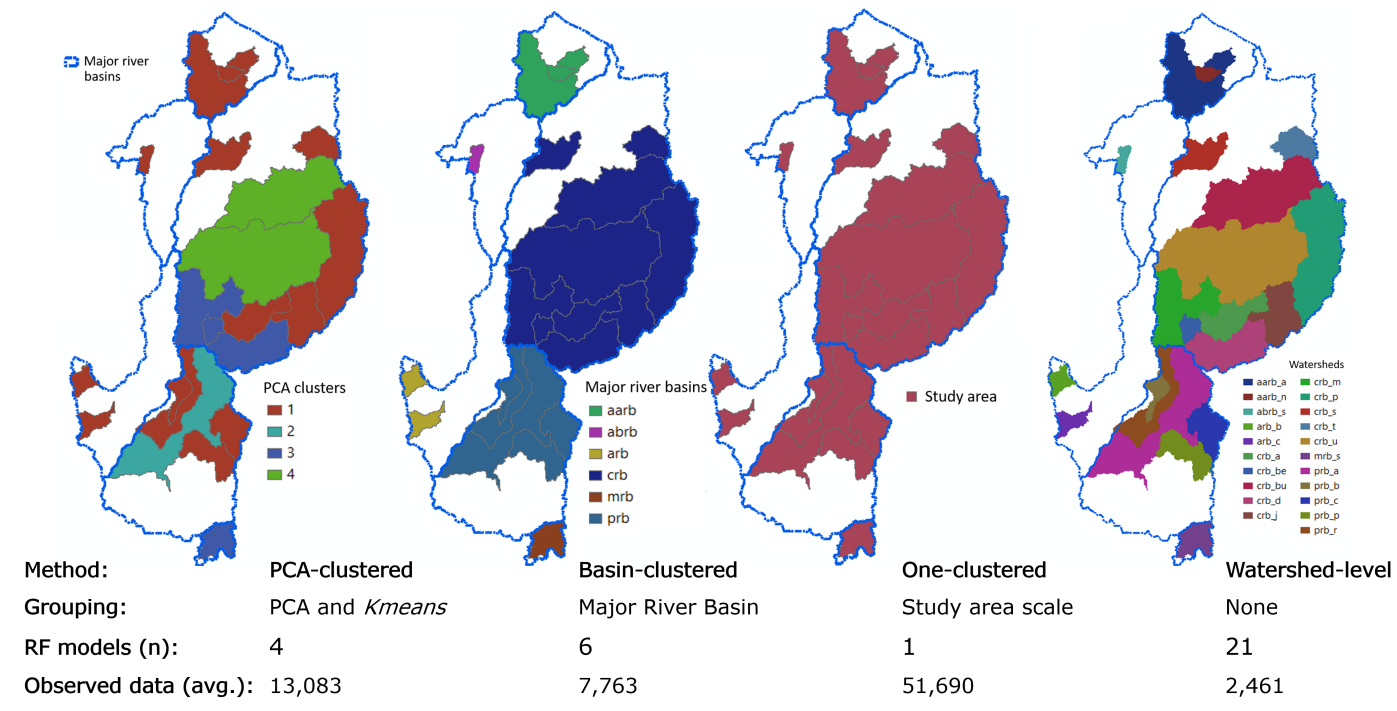

Figure 4. Maps of watershed grouping methods as basis for regionalizing RF models. Indicated on each method are the number of RF models and the average observed data per RF model.

\section{Clustering by PCA}

As mentioned, the PCA-clustered method relied the watershed grouping based on principal components in light of finding homogeneous watershed clusters (Kahya et al., 2008). This method "normalizes" the watersheds based on the least possible variability among the watershed value tables (also known as dimension reduction). From this, PCs are constructed and interpreted on a dimensionless planar coordinate system with $x$ and $y$ axis as the first and second PCs (PC1 and PC2) - the components that captures most information of the watersheds. Inside this "PC graph" are the normalized watersheds, plotted and labelled by watershed names. From that, watersheds are clustered using K-means algorithm (Hartigan \& Wong, 1979), an unsupervised and distance-based clustering method. Clustering depends on how close the watersheds are to the cluster centroid in the PC graph. Centroids are assigned at locations with the least variability among surrounding watersheds. The gap between the centroid and the watershed is measured by a straight line (Euclidean distances) in multiple iterations. The confidence of the clustering is measured when within-cluster variation is minimized, which is measured by the sum of squares (SS) computed by :

$$
\sum_{k=1}^{K} \sum_{i \in c_{k}}\left\|w_{i}-m_{k}\right\|^{2}
$$

where at the PC graph, centroids are $m_{1}, m_{2}, \ldots m_{k}$, watersheds are $w_{i}=\left(w_{i 1}, \ldots w_{i p}\right)$, and clusters are $c_{1}, c_{2}, \ldots c_{k}$.

We first tested the optimal number of clusters, measured by average "silhouettes", to evaluate the distinction power per cluster number (Rousseeuw, 1987). Out 
Table 2. Cluster assignments of watersheds along with other key watershed descriptor and information. Climate types include type 1 (distinct wet and dry), type 3 (less pronounced wet and dry), and type 4 (rainfall is more or less distributed yearly). The water (regulating) infrastructures consist of dams, water impounding structures, small reservoirs, and so on.

\begin{tabular}{|c|c|c|c|c|c|c|}
\hline Watershed & $\begin{array}{l}\text { PCA } \\
\text { cluster }\end{array}$ & Size (ha) & $\begin{array}{l}\text { Dominant } \\
\text { climate }\end{array}$ & $\begin{array}{l}\text { Cropland, for- } \\
\text { est, grassland } \\
\text { proportions (\%) }\end{array}$ & $\begin{array}{l}\text { Mean stream- } \\
\text { flow }\left(\mathrm{m}^{3} / \mathrm{s}\right)\end{array}$ & $\begin{array}{l}\text { Water in- } \\
\text { frastructures } \\
\text { (number) }\end{array}$ \\
\hline aarb_a & 1 & 236,119 & Type 3 & $5,93,2$ & 228 & 3 \\
\hline aarb_n & 1 & 19,277 & Type 3 & $0,99,1$ & 17 & 0 \\
\hline abrb_s & 1 & 20,143 & Type 1 & $17,81,1$ & 3 & 0 \\
\hline arb_b & 1 & 31,609 & Type 1 & $35,44,1$ & 3 & 0 \\
\hline arb_c & 1 & 36,507 & Type 1 & $23,74,2$ & 19 & 0 \\
\hline crb_a & 1 & 104,525 & Type 4 & $24,70,6$ & 65 & 2 \\
\hline crb_be & 3 & 27,211 & Type 3 & $13,84,2$ & 3 & 4 \\
\hline crb_bu & 4 & $1,851,853$ & Type 3,4 & $30,63,1$ & 784 & 15 \\
\hline crb_d & 3 & 169,590 & Type 3,4 & $6,92,1$ & 53 & 0 \\
\hline $\mathrm{crb}_{-} \mathrm{j}$ & 1 & 293,539 & Type 4 & $15,84,2$ & 210 & 1 \\
\hline crb_m & 3 & 215,601 & Type 1 & $11,87,1$ & 127 & 15 \\
\hline crb_p & 1 & 317,514 & Type 4 & $12,85,2$ & 415 & 0 \\
\hline crb_s & 1 & 85,267 & Type 3 & $2,97,1$ & 45 & 2 \\
\hline crb_t & 1 & 66,994 & Type 4 & $10,75,4$ & 52 & 5 \\
\hline crb_u & 4 & $1,187,381$ & Type 3,4 & $33,61,6$ & 454 & 15 \\
\hline mrb_s & 3 & 63,445 & Type 1 & $14,82,3$ & 34 & 1 \\
\hline prb_a & 2 & 622,280 & Type 1,3 & $51,43,2$ & 281 & 7 \\
\hline prb_b & 1 & 37,406 & Type 1,3 & $82,12,6$ & 9 & 1 \\
\hline prb_c & 1 & 84,287 & Type 3,4 & $15,83,2$ & 78 & 0 \\
\hline prb_p & 1 & 85,739 & Type 1 & $42,54,4$ & 120 & 0 \\
\hline prb_r & 1 & 147,804 & Type 1 & $72,25,3$ & 47 & 1 \\
\hline
\end{tabular}

of five possible clusters ( 2 to 6 ), we chose the median value (cluster $=4$ ) to consider both cluster number (n) and distinction power (silhouette value tipping point). This clustering explained $80 \%$ of the dataset variability, computed by dividing between cluster SS from total SS. The importance of the clustering to each observation (watersheds) is measured by cosine squared (cos2) (Abdi \& Williams, 2010).

The watershed clusters and other key information per watershed are shown in Table 2. The clustering, in general, can be attributed to the homogeneity from general watershed characteristics - size, climate, main land covers and streamflow information.

\subsection{Models evaluation}

As in other regression model tasks, we assessed which among the four methods leads to better RF model regionalization by evaluating the RF models per watershed. To evaluate, we used a randomly held-out $20 \%$ out of total observed streamflow data from each of the 21 watershed for comparison with the predicted streamflow. We perceived this proportion to be sufficient in retaining the integrity of unseen data given the high variability in our study area and a long observed streamflow time series from 2000 to 2016. Also, ideal data on other local streamflow stations in the Philippines are 
unavailable yet. We performed per watershed evaluation and a one-time evaluation using each held-out and the accumulated held-out watershed data, respectively. This two-way evaluation provides inter-method and inter-watershed comparison.

Three accuracy metrics were used for evaluation, reported in summary tables. First is the coefficient of determination or $R^{2}$ (equation 3) computed as 1 minus the squared difference between the observed $y_{i}$ and predicted streamflow $\hat{y}_{i}$; divided by the squared difference of $y_{i}$ and the mean observed streamflow $\bar{y}$. Second, we used Nash Sutcliffe Efficiency or NSE (equation 4), computed similarly to $R^{2}$ - but instead of $y_{i}$ - denotes the predictions as $y_{i, s i m}$. The former is a goodness-of-fit measure of a regression model since we used RF for regression, while the latter measures how well a "model simulation" can predict streamflow relative to $\hat{y}_{i}$. We used these relative coefficients to make results comparable to all watersheds. Though (H. V. Gupta et al., 2009) suggested caution in using NSE to evaluate streamflow models in highly seasonal areas, the high spatio-temporal properties of the watersheds (this study) and randomness in selecting evaluation data could compensate for that $(\mathrm{H}$. V. Gupta et al., 1998). Lastly, we used Percent Bias $(P B I A S)$ to give an overview whether the RF models over or underestimate the predicted streamflow. PBIAS should be 0.0 to be optimal and is computed in equation 5 using the previously mentioned components.

$$
\begin{gathered}
R^{2}=1-\frac{\sum\left(y_{i}-\hat{y}_{i}\right)^{2}}{\sum\left(y_{i}-\bar{y}\right)^{2}} \\
N S E=1-\frac{\sum\left(y_{i}-y_{i, s i m}\right)^{2}}{\sum\left(y_{i}-\bar{y}\right)^{2}} \\
P B I A S=\frac{\sum\left(y_{i}-y_{i, s i m}\right) * 100}{\sum\left(y_{i}\right)}
\end{gathered}
$$

The regionalization methods were also evaluated relative to the major river basins and other categorical watershed characteristics. The former is useful in the context of river basin management in the Philippines, while the latter attempts to find physical and climatic causality from the results.

\subsection{Variable importance}

The main advantage of $\mathrm{RF}$ as a machine learning algorithm is to give an importance value to the covariates. RF provides variable important measure (VIM) as a model output, measured by mean decrease in accuracy and equivalent to the "predictive power" of a covariate. This works by permuting a covariate of interest while the rest have their original values. This gives a new prediction in the end and compared with that of the original (no-permutation) model using RF's test (out-of-bag) data or $1 / 3$ of the total watershed value table. The comparison gives an average error rate difference with and without permutation. The higher the value, the more the covariate influences the model (Breiman, 2001). 
VIM was assessed separately for static and dynamic covariates since permutation can be more sensitive to dynamic variables (Altmann et al., 2010). This could overshadow the added-value of static covariates in RF model regionalization. As such, the VIM of static and dynamic covariates were summarized both in absolute values per covariate and \% breakdown per covariate category (e.g. season, land cover, slope, elevation).

\subsection{Uncertainty assessment}

Uncertainty is a range of possible predicted streamflow where the true streamflow lies and therefore should be accounted. In this study, we reported uncertainty through confidence intervals relative to a random forest tree. Recall that a streamflow prediction is the mean of all tree predictions in a random forest. To estimate CI, we used the infinitesimal jackknife (IJ) modified by (Wager et al., 2014) and integrated in the ranger package. The modified $I J$ approach deals with the uncertainty influenced by the covariates redundancy and limit (split variable) during tree growing, and an inherited noise when bootstrapping the watershed value tables - both cannot be dealt by tuning the RF hyperparameters e.g. split variable alone. This is relevant to our covariates of choice because those with yearly values are duplicated more than a daily value. The modified $I J$ is written as:

$$
\widehat{V}_{I J}^{\infty}=\sum_{i=1}^{n} \operatorname{Cov}_{*}\left[N_{i}^{*}, t^{*}(x)\right]^{2}
$$

where the variance of a random tree $\widehat{V}_{I J}^{\infty}$ is a function of the covariance $\operatorname{Cov}_{*}\left[N_{i}^{*}, t^{*}(x)\right]$ between the random tree $t^{*}(x)$ and $N_{i}^{*}$ covariate multiple entries in a bootstrap sample the $i^{t h}$ times. To derive the CI at $95 \%$ denoted as $C I^{95}$, the predicted streamflow $\hat{y}_{i}$ is added or subtracted to the product of 1.96 and the $\sqrt{\widehat{V}_{I J}^{\infty}}$ as shown in equation 7 . We also derived the percent coefficient of variation (CV\%) as an uncertainty summary statistic per regionalization method, where the $\sqrt{\widehat{V}_{I J}^{\infty}}$ is divided by the mean predicted streamflow $\bar{y} i$ multiplied by 100 (equation 8 ).

$$
\begin{gathered}
C I^{95}=\hat{y}_{i} \pm 1.96 * \sqrt{\widehat{V}_{I J}^{\infty}} \\
C V \%=\sqrt{\widehat{V}_{I J}^{\infty}} / \bar{y} i * 100
\end{gathered}
$$

After estimating $C I^{95}$, we further analyzed the comparison of observed and predicted streamflow. Using one-time evaluation results, we graphed the comparison relative to a 1:1 line and zoomed into error-prone streamflow ranges. To further analyze, we made a hydrograph of a certain year to spot seasonal errors that are systematic (bias). To highlight seasonal bias, the comparison was aggregated into monthly flows to partially remove random errors (Hamilton \& Moore, 2012). Per month and per regionalization method, standardized residuals (SR) were derived to make seasonal 
results comparable. SR is derived by dividing the residuals $\left(y i-\hat{y}_{i}\right)$ over the uncertainty $\sqrt{\widehat{V}_{I J}^{\infty}}$. Negative values indicate streamflow overestimation while positive values denote underestimation. We then created figures of monthly SR per regionalization method in a line graph and per watershed in box plots where the lower and upper hinges correspond to the $25^{\text {th }}$ and $75^{\text {th }}$ quartiles. Aside from seasonal bias, we also looked at bias on extreme flows using 50 highest flows of the evaluation data.

$$
S R=y i-\hat{y}_{i} / \sqrt{\widehat{V}_{I J}^{\infty}}
$$

\section{Results and discussion}

\subsection{Evaluating the regionalization methods}

Overall, the observed and predicted streamflow were correlated in all regionalization methods; but the goodness-of-fit indicators varied per method. Results of one-time evaluation indicated that the PCA-clustered method had the highest accuracy, with at most 0.35 and 0.31 higher $R^{2}$ and $N S E$; and at most $5 \%$ less bias than other methods. Results of basin-clustered and one-clustered methods were identical while watershed-level method was the least accurate. Same outcome was observed in watershed-level evaluation, where the PCA-clustered method showed the highest accuracy in majority (14 of 21) of the watersheds. This method also had the lowest standard deviation (SD) from the three accuracy metrics, suggesting consistency in per-watershed results. Notably, higher accuracy margin was observed in 6 of the mentioned 14 watersheds, outperforming the other models e.g. by $0.25 R^{2}$, on the average. In contrast, the watershed-level method was the least accurate in 20 out of 21 watersheds and with the highest results' SD. Per watershed results of basin-clustered and one-clustered methods were similar on the average, but varied per watershed. While there was no watershed from the PCA-clustered below the significant thresholds for $R^{2}$ and NSE (0.6 and 0.5, respectively), there were rare cases that PCA-clustered had high $P B I A S$ e.g. $a b r b \_s$ and $a r b \_b$.

Results slightly varied when analyzed in the context and scale of major river basins. The PCA-clustered method favored basins aarb and crb, e.g. having 0.24 and 0.15 higher $R^{2}$ than the second-best method. Watersheds inside the latter basin also had the most improvement, with 0.49 and 0.26 increase in $R^{2}$ and $N S E$, on the average, when using PCA method. Interestingly, the basin-clustered was on par with PCA-clustered for arb and $p r b$, just 0.02 less $R^{2}$ for both basins. Similarly, the PCA-based method was identical with one-clustered in cases of $m r b$ and $a b r b$.

The results were also analyzed according to climate type, watershed size, and watershed clusters (see Table 2). In terms of climate, the PCA method was favorable for all the climate types especially those under type 4 climate (distributed rainfall, year) with $0.30 R^{2}$ more than the second-best method. In terms of size, the PCAclustered method was better for relatively small and large watersheds with 0.13 and $0.09 R^{2}$ more than the second-best. In terms of the watershed clusters, it favored its own method being at least $0.10 R^{2}$ ahead from the next-best method. Defying the common finding was watershed $p r b_{-} c$ in cluster 3 , favoring the basin-clustered method. 
More generally, the accuracy results seemed to be independent to the number of training (and evaluation) data. The two were uncorrelated at only $0.01 R^{2}$ when regressed. On a different note, despite the similarity of $R^{2}$ to $N S E$, there were watersheds with higher gaps between the two metrics. Examples are $a b r b \_s$ and $c r b \_u$ with at least $0.05 R^{2}-N S E$ gap consistent among the four methods. The first happens to be smallest watershed; while the second is not only one of the largest, but also a lone cluster. This suggests that NSE reacts better to inter-watershed variability than $R^{2}$. 


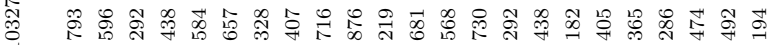

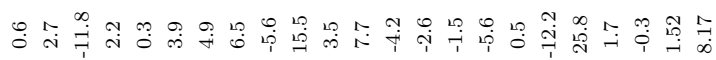

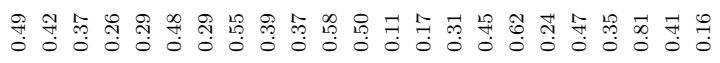

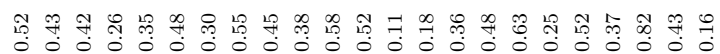

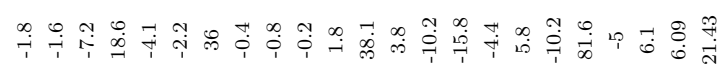



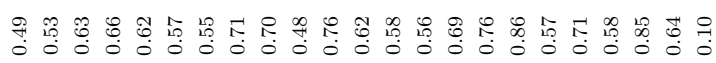

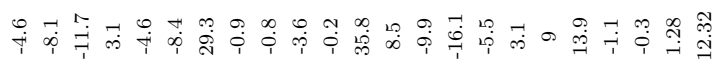

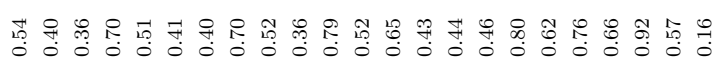

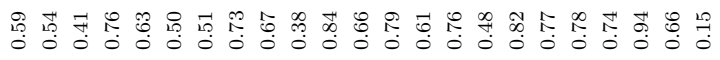

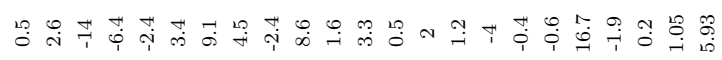

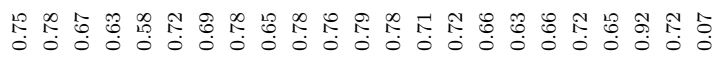

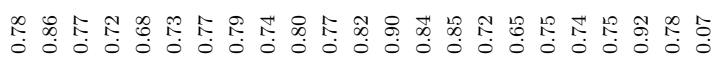

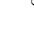




\subsection{Watershed clustering effect}

The PCA-clustered method that outperformed the other methods can lead to the following realizations: (1) homogeneously clustered watersheds can lead to better RF model regionalization, (2) high watershed variability at major river basins and Luzon scales, and (3) watershed-level method is often inadvisable in data-driven methods.

In discussing the first observation, the watershed clustering scheme should be linked to the watershed characteristics. Figure 5 shows how the covariates correlate with the PCs and with themselves in a $2 \mathrm{~d}$ space (also called as contributions). These confirm the $80 \%$ variability explained (in section 4.2 ) by land cover and physical covariates during the clustering, as they were correlated with the PCs and clumped in the contributions graph. This suggests that the watershed clustering is more of a biophysical representation. The review by Beck et al., (2016) about the history of regionalization highlighted that regionalizing based on similar attributes are effective and even more effective when using single models. Related findings in literature both affirmed that watershed physical features like slope, elevation, and forest cover greatly influence a PC-based watershed clustering scheme (Chiang et al., 2002; Razavi \& Coulibaly, 2013). More complex methods combine physical and streamflow signatures to cluster watersheds e.g. (Boscarello et al., 2016). Since streamflow signatures were not included in our clustering due to data limitation, the relevance of streamflow in watershed clustering is confined with the high correlation of daily streamflow (O.obs) to principal components (see Figure 5 again). Nevertheless, knowing that streamflow is linked with the biophysical data is a good sign in the PUB context. Ungauged watersheds could use regionalized RF models e.g. PCA-clustered 1 assuming that ungauged watershed is assigned to cluster 1 . That would only require ungauged watersheds to have consistent covariates like the 55 covariates (this study) - all from open data.

A homogeneous cluster out of watershed physical features can result in two things. One is the imbalance in the number of watersheds per clusters; second is cross-basin grouping where two watersheds apart and belonging to separate basins can be grouped. For instance, PC-based clustering by (Chiang et al., 2002) resulted into a cluster with 59 watersheds and a cluster with one watershed. Similarly (Razavi \& Coulibaly, 2013) had a cluster of 37 and another with seven. We can relate from these examples as we have two low-count clusters. In particular, cluster 4 has two watersheds which are both forested; and both with high streamflow and regulated flows. Another cluster only had one watershed, the only large agricultural watershed from the study area. This further suggests that a neighbor-based clustering (spatial proximity) would not be the first option in our study area. On the other hand, we also noticed some flaws from the PCA-clustered method. Two watersheds, $a b r b_{-} s$ and $a r b_{-} b$, had relatively high PBIAS despite high $R^{2}$ and NSE. These are two of the smallest and highly seasonal watersheds mixed in cluster 1 . If another cluster is to be made (cluster $=5$ ), the two could be isolated. This shows that an optimal watershed clustering involves modelling choices, which should follow best-practices e.g. parameter tuning and iterations especially when upscaling the study. 
For the second observation, we assert that homogeneity is not assured at basinlevel as watershed characteristics and response can abruptly change in space (He et al., 2011). This is echoed from our results where the basin-clustered method was 0.21 less $R^{2}$ than the PCA-clustered method and either second or third best model in basin-level results. This can either be attributed to lack of watershed representation in basins or gaps in time series data (e.g. arb, abrb, aarb, and $m r b$ ). Nevertheless, limitations on data gaps and representation are not evident in basin $c r b$ - the largest, best represented, and densely gauged basin - which performed best in PCA-based model. This suggests that $c r b$ can be the most variable basin and this variability is worsen by the presence of water-regulating structures (see Table 2). An exception is basin prb, an agricultural basin with less feature variability and fewer water-regulating structures. Similar to the basin-clustered model, the results of the one-clustered model hints that even a lumped watershed information can be insufficient to predict streamflow accurately. Logically, this is the case where watershed variability is at most because of ungrouped and mixed watershed information. In relation, we found that the number of training (and evaluation) data was a non-factor in predicting streamflow accurately. This implies the complexity in "learning" the hydrologic system, where big data could still be insufficient if there is no watershed clustering. Though there are seldom cases where one-clustered method was the best regionalization method e.g. prb_a and basin $m r b$. But by consistency measures, the method choice can still go to the PCA-clustered method.

That is more advisable when the choices include the watershed-level method. The main reasons why watershed-level was the least accurate is due to data scarcity and regionalization itself. watershed-level methods produce stand-alone watershed models trained from a single watershed value table with data gaps. This makes an independent model and literally non-regional, and we say more ideal in process-based and less ideal in data-driven methods. In data-driven methods though, gaps in observed data can be compensated because of watershed regionalization.

\subsection{Important covariates}

In data-scarce basins, the effect of regionalization, regardless of the grouping scheme, can have added value. Information from other watersheds benefited the PCAclustered, basin-clustered, and one-clustered methods, being way more accurate than the watershed-level method. This can be reflected by the Variable Importance Metric (VIM) given by RF models, which indicates the predictive power of a covariate the way it affects model accuracy once permuted. In watershed-level models, static covariates had 0 VIM values logically because they are static or singled-value - and so in bootstrapped samples - making permutation nonsensical. In other words, $75 \%$ of total covariates are of no-use in model prediction. But when watershed information are grouped, the VIM values of static covariates increased from 0 to $22 \%$ VIM e.g. in a lumped grouping of one-clustered method. From this, Figure 6 shows both absolute and relative VIM values for static and dynamic covariates. The relative value (\% breakdown) is the summary of VIM average per covariate category. 

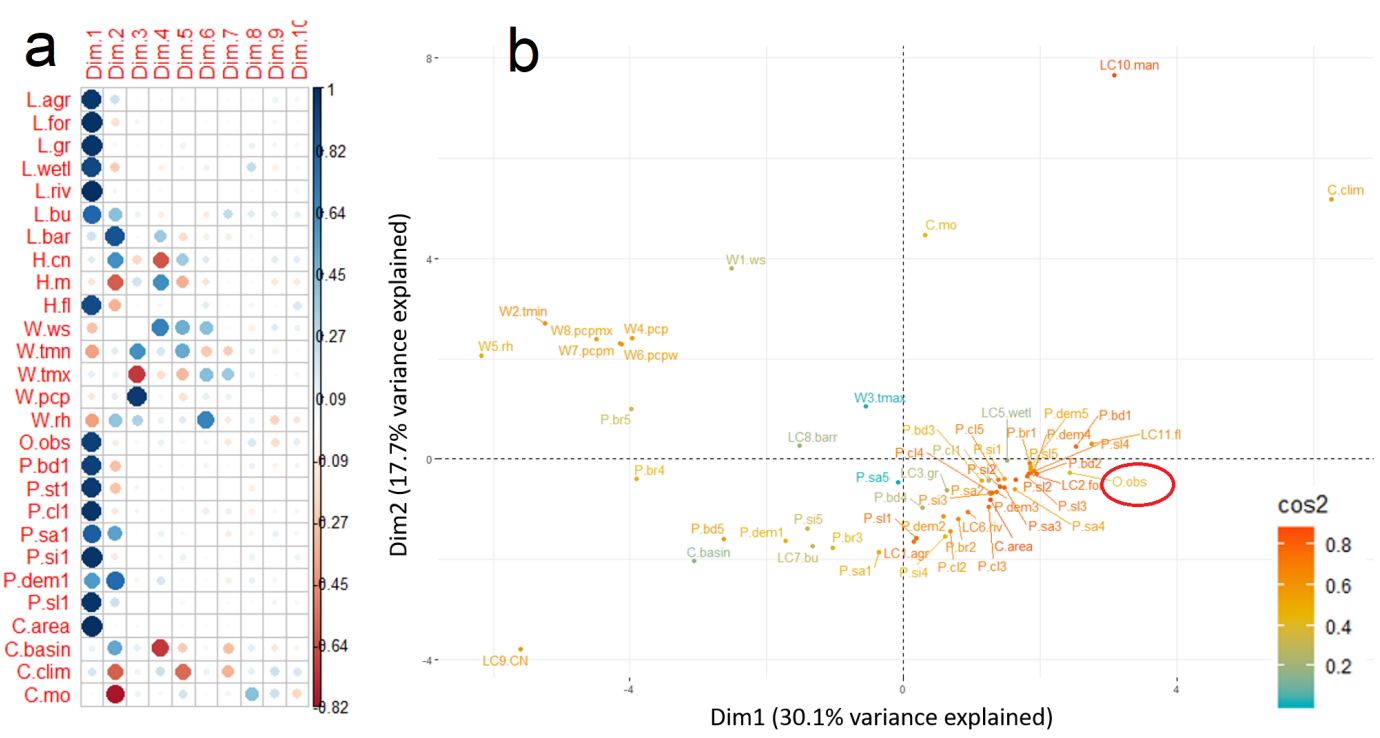

Figure 5. (a) Collinearity of the covariates to the PCs - also labelled as Dim - showing how physical covariates ( $P$ and $L$ labels) correlate with the main PCs Dim1 and Dim2. It shows one class per physical covariate because results are similar among the 1-5 classes; (b) Collinearity of all covariates at 2d space of Dim1 and Dim2 showing how physical covariates are clumped, and along with streamflow (O.obs, encircled). Clumped covariates influence the watershed clustering the most. High cos2 orange colors means better agreement of PCs to the covariate locations.

The topmost static covariates based on VIM were bulk density, clay, elevation, sand, silt, and slope. VIM appears to be sensitive on dominant covariates (Altmann et al., 2010), which complements the watershed grouping scheme out of physical variables. In particular, very low bulk density (p.bd1) and very high clay soil (P.cl5) had the highest VIM scores. High clay and low bulk density are naturally coinciding (S. C. Gupta \& Larson, 1979) and these characterize most headwaters of our study area. This further reflects that the RF model could relate to some theoretical impacts of static covariates to streamflow. For example, clay soils can hold more water and more regulated run-off (Greacen \& Sands, 1980) and watersheds in high altitudes have more rain (Winiger et al., 2005). This is highlighted in Figure 3 in a decision tree context. These realities can also be analyzed in parallel with land cover change. Moreover, sensitivity analysis and co-dependence of covariates to streamflow can give a shed of causality in interpreting RF models (Borgonovo et al., 2017) (Greenwell, 2017).

The VIM of the dynamic covariates were dominated not only by forest land cover class but also by seasonal and weather covariates, contributing $66 \%$ of the VIM total. This suggests that RF models are highly sensitive to seasonal weather patterns in the region. Same is observed with other RF models of (Yang et al., 2016), (Reynolds \& Shafroth, 2016) where the most dynamic variables were also the most sensitive to VIM. This seems logical given that daily weather data, for instance, have wider range of permutation values than yearly data. Higher temporal resolution is likely the reason why dynamic covariates have higher VIM values than static covariates. For instance, 
forest cover (L.for) became dynamic due to net changes from yearly forest loss, thus increasing its VIM. High forest cover (and changes) of the study area in the past 16 years may have resulted this model sensitivity. As mentioned, land cover change and forest loss effect to streamflow would be interesting to analyze next.

High RF model sensitivity to season and weather covariates can be reflected also during watershed clustering. These covariates dominated the third PC while other dynamic variables appeared until PC 6. This shows how uncorrelated these covariates are from the PCs and the most useful if data-trimming will take place (Chiang et al., 2002). However, in our case, PCA was used for clustering and not for data reduction. The potential overfitting out of correlated covariates are dealt when the split variable and number of trees of RF were tuned to an optimal value. Moreover, random forest automatically de-correlates trees at the most, being lesser prone to multicollinearity (Breiman, 2001).

One key message of this section is the added-value from the static covariates after watershed grouping. These data inputs are all open data, complementing the datadriven method to model streamflow. Moreover, these inputs are relatively very high resolution and therefore advantageous than coarser inputs e.g. the $250 \mathrm{~m}$ soil inputs used in this study was found to capture soil dynamics better in streamflow modelling (Duku et al., 2015). The advantages from input data can lead into cross-region and even cross-country regionalization.

Worth emphasizing also are the advantages in using random forest via ranger package. Aside from giving importance values, another advantage when using RF is to estimate the uncertainties in predicted streamflow. 

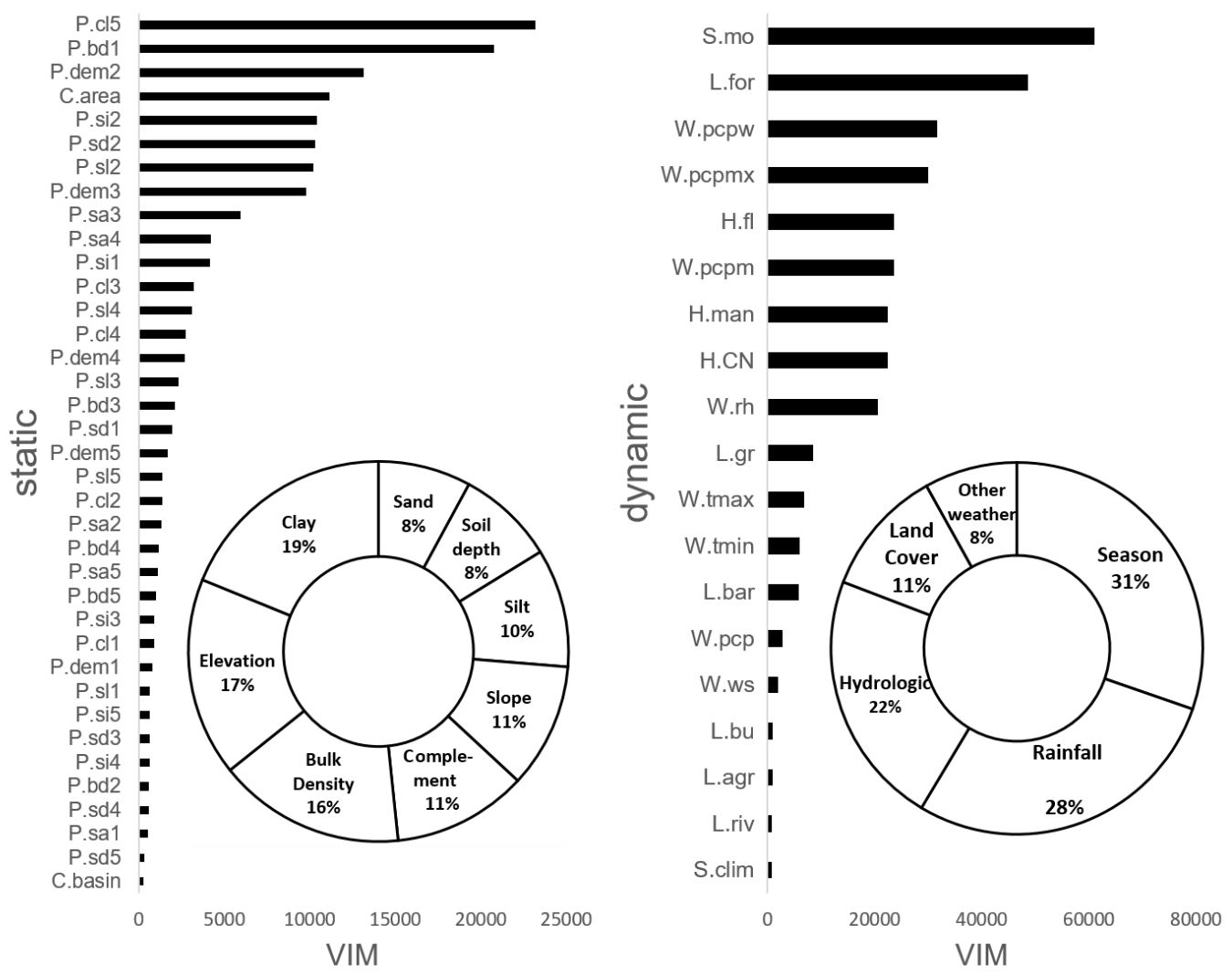

Figure 6. Variable importance measure of static (left) and dynamic (right) covariates of the one-clustered method where the most watershed information are. The bar graphs depict the absolute VIM value per covariate while the pie-charts are summary of \% breakdown of VIM average values (uni per covariate category. 


\subsection{Uncertainty of random forests and seasonal bias}

Despite tuning RF hyperparameters, there remains risks from biased bootstrapping and tree growing in using dense (and correlated) watershed value tables to create RF models. For accountability, we estimated uncertainties in predicted daily streamflow using the modified $I J$ approach.

Error assessment is an important post-modelling steps in streamflow modelling (Abbaspour et al., 2017). Shown in Figure 7 are the results of one-time evaluation of the four regionalization methods with the following sub-figures: (a) predicted streamflow and its confidence intervals $\mathrm{CI}^{95}$ aggregated to calculate the $\mathrm{CV} \%$; (b) zoomed-in results until $1000 \mathrm{~m}^{3} / \mathrm{s}$; and (c) evaluation result in a sample year (2006, all watersheds data) to highlight over and under estimation.

In Figure 7(a), watershed-level method had the least uncertainty (13\% less at least) among others, followed by the PCA-clustered, one-clustered, and basin-clustered methods. This is potentially caused by the trade-off between grouping and not grouping watershed information. The CI are computed to account for the minimized noises and bias of the bootstrapping procedures (Wager et al., 2014). Given that watershedlevel value table for model training is unmixed with other watersheds, it can have less variable random subsets. Same logic is applicable on why the clustered (more homogeneous) was the least uncertain among models with watershed grouping. Another noticeable result was the higher uncertainty from the highest or extreme flows. These flows are outcomes of heavy rainfall e.g. typhoon season from July to October, occurring several times in a year (Cinco et al., 2018). Being the minority among the flows can result into higher uncertainty, related to streamflow data imbalance or histogram skewness (Bhattacharyya, 2013). This is quite common in streamflow data especially in areas with very pronounced season. In cases where certain predictions of extreme flows are needed for specific applications like flood modelling, observed streamflow should adhere to sampling protocols (Tian et al., 2013) and prefer data with higher temporal resolution e.g. hourly (Saadi et al., 2019).

Also observable from the figures are systematic over and under estimation of streamflow (bias). Using averages of the 50 highest flows, we derived underestimation of extreme flows to be 53\%,113\%,120\%, and 127\% from PCA-clustered, basinclustered, one-clustered, and watershed-level methods, respectively (see full hydrograph in Appendix B). While these flows seem to be the most uncertain and underestimated, as mentioned, these are minority flows. For general streamflow modelling applications (e.g. water resources accounting) unlike flood mitigation, extreme flows can be averaged out. The more prominent error source was the overestimation until around $1000 \mathrm{~m}^{3} / \mathrm{s}$, as highlighted in Figure 7(b). The correction of these relatively lower flows was more evident in PCA-clustered method. In a sample year in Figure 7 (c) (full time series in Appendix B), reduced overestimation of low flows and reduced underestimation of high and extreme flows were also evident in PCA-clustered. Nevertheless, analysis of bias gets clearer when looking at aggregated flows.

The predicted streamflow was analyzed per month to understand bias related to seasonal patterns. This analysis per regionalization method is shown in Figure 8, while the results per watershed are shown in Appendix A. Visualizing monthly streamflow 

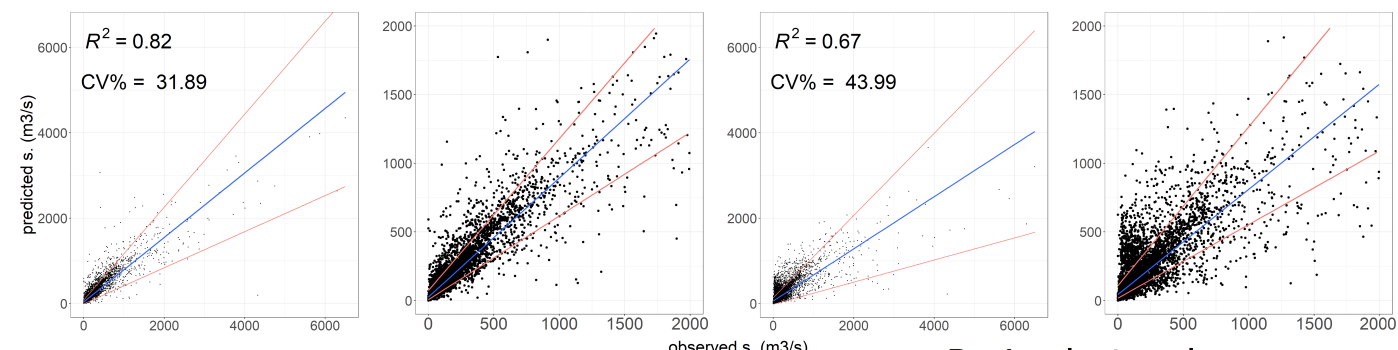

PCA-clustered
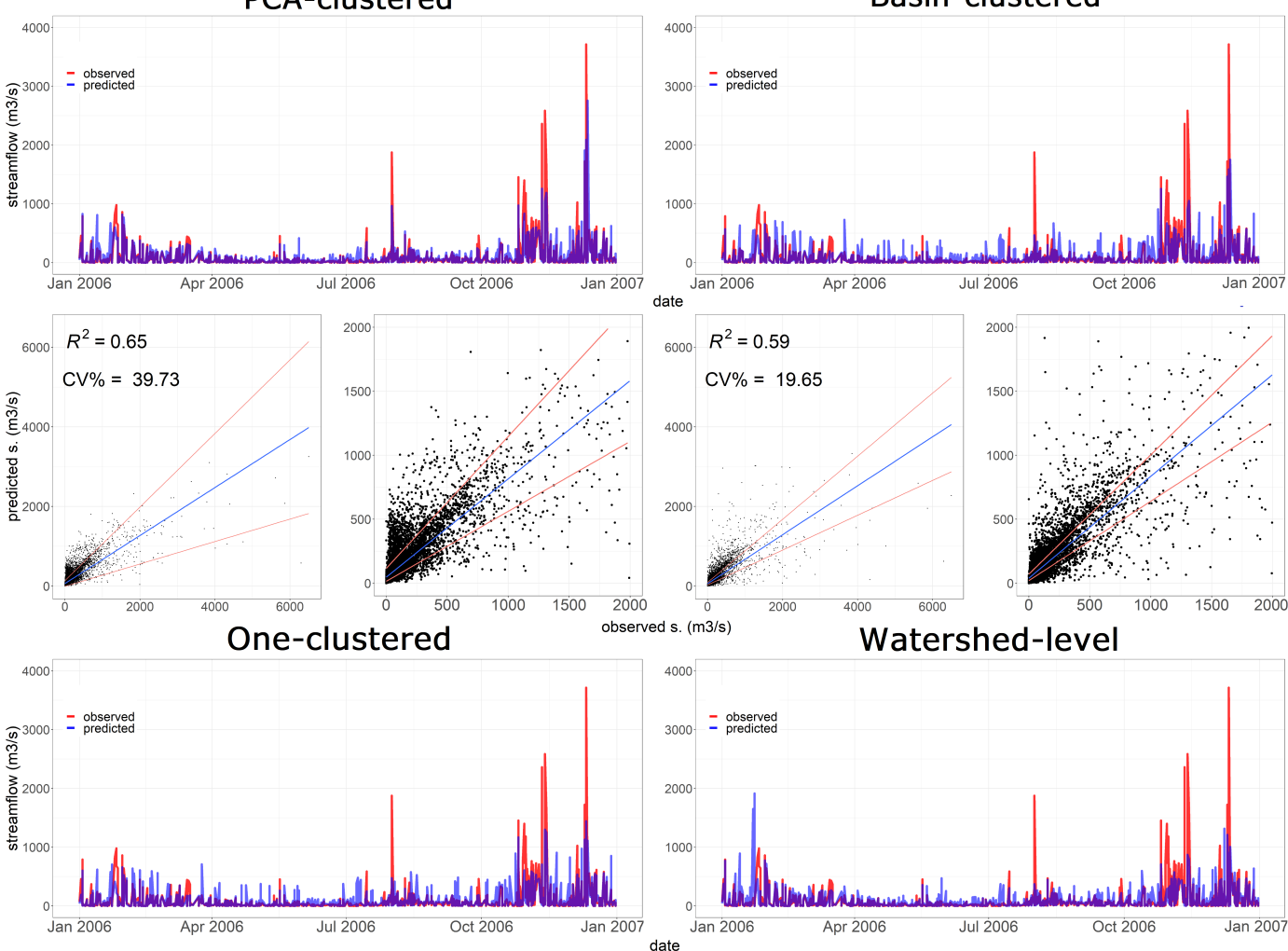

Figure 7. Evaluation results of the four regionalization methods using the accumulated $20 \%$ held-out data of watersheds to highlight uncertainty and errors: Upper left graph (a) shows the all predicted and observed streamflow comparison with $\mathrm{CI}^{95}$ range, and the $\mathrm{R}^{2}$ and $\mathrm{CV} \%$. Upper right graph (b) zooms to below $1000 \mathrm{~m}^{3} / \mathrm{s}$ flows to highlight the systematic trend or bias. Lower graph (c) shows time-series of the observed and predicted streamflow in year 2006. The full time series hydrograph is shown in the appendices.

is also strategic in the sense that the RF models were very sensitive to month (C.mo) covariate. Using the monthly flow aggregates, we first compared the standardized residuals, calculated in equation 9. In general, the graph depicts streamflow overestimation in all models and most months. Similar to the evaluation results, the clustered model was the least bias in 8 out of 12 months.

Seasonally, the monthly bias graph depicts three trends common to the four regionalization methods: (1) overestimation during the dry season of March until June, (2) brief underestimation during monsoon season from November to January, (3) lower bias in wettest months of July to September. In these cases, streamflow predictions 
can be reactive to seasonal weather patterns (Singh, 1997). On the other hand, streamflow models can also capture non-linear watershed behaviors. For instance, predicted streamflow did not increase despite heavy rains because of water storage effect in the landscape (Shortridge et al., 2016). In theory, streamflow should increase after rainfall events. However, in times of high streamflows even without rainfall, streamflow can be influenced by both natural and man-made water regulations.

The first observation can be linked to the effect of water-regulating structures, mainly dams for irrigation, which release water particularly during the first cropping season $\left(1^{\text {st }}-2^{\text {nd }}\right.$ quarter $)$ and vary in water release schedules. These structures often exist in watersheds with relatively large lowland agriculture e.g. aarb_a, crb_bu, $c r b \_m, c r b_{-} u$, and $p r b_{-} a$. Despite having higher errors in dry months, these watersheds benefited from watershed clustering and performed poorest using watershed-level model. A watershed-level model can be more inadvisable when watersheds have waterregulating structures by having no extra information to compensate for irregular flow time-series and data gaps. In any future attempts to minimize dam effects, streamflow signatures from flow duration curves could be included in watershed clustering as well as dam-related data as covariates (assuming data availability).

For the second observation, after the wettest months, the aquifers and shallow groundwater becomes full, thus retaining relatively higher streamflow even without rains. Moreover, the study area is affected of northeast monsoon making December to February the coolest months. Soil moisture evaporation is less pronounced in lower temperatures thus retaining high streamflow (Penman, 1948). This scenario was more pronounced in watersheds from basins aarb and crb - the northeast basins in the study area. Moreover, dams tend to release excess water during this season resulting into above-average streamflows. To model these realities, temporal memory effects and spatial weather inputs could be integrated, resulting into a spatio-temporal streamflow models.

While the first two observations are linked to non-linear realities, the last observation is related to a linear rainfall-runoff scenario, where streamflow is reactive to rain events. In the study area, raining often starts in June and this month was also the tipping point to reverse high errors from dry months. This behavior is common to all watersheds, but more reactive to this seasonal transition are smaller watersheds with minimal regulating structures e.g.abrb_s,arb_b, $a r b_{-} c, c r b \_t, p r b \_b, p r b \_r$. Smaller watersheds seem to adhere more in rainfall-runoff events than larger ones. To exemplify, one study used a linear model in a small watershed to forecast drought (Tigkas et al., 2012) while another reported a more pronounced response of smaller watersheds to land cover change (Dias et al., 2015). As mentioned, assessing forest loss effects in different watershed sizes would be an interesting follow-up to this study.

The seasonal bias can also be affected by errors and associated uncertainty from gauged data. While we treated this data as ground-truth, this dataset have been computed indirectly from water depth or stage and curve ratings (JICA, 1998). In a study by (Horner et al., 2018), this kind of measurement can introduce non-negligible systematic errors in addition to negligible man-made errors and negligible non-systematic measurement errors. Accounting this root error source could be difficult given that 
raw data are often inaccessible. What is more, $\mathrm{RF}$ model predictions can be bias to the mean of the dataset resulting into systematic errors, but can be dealt at model-level bias correction methods (Zhang \& Lu, 2012).

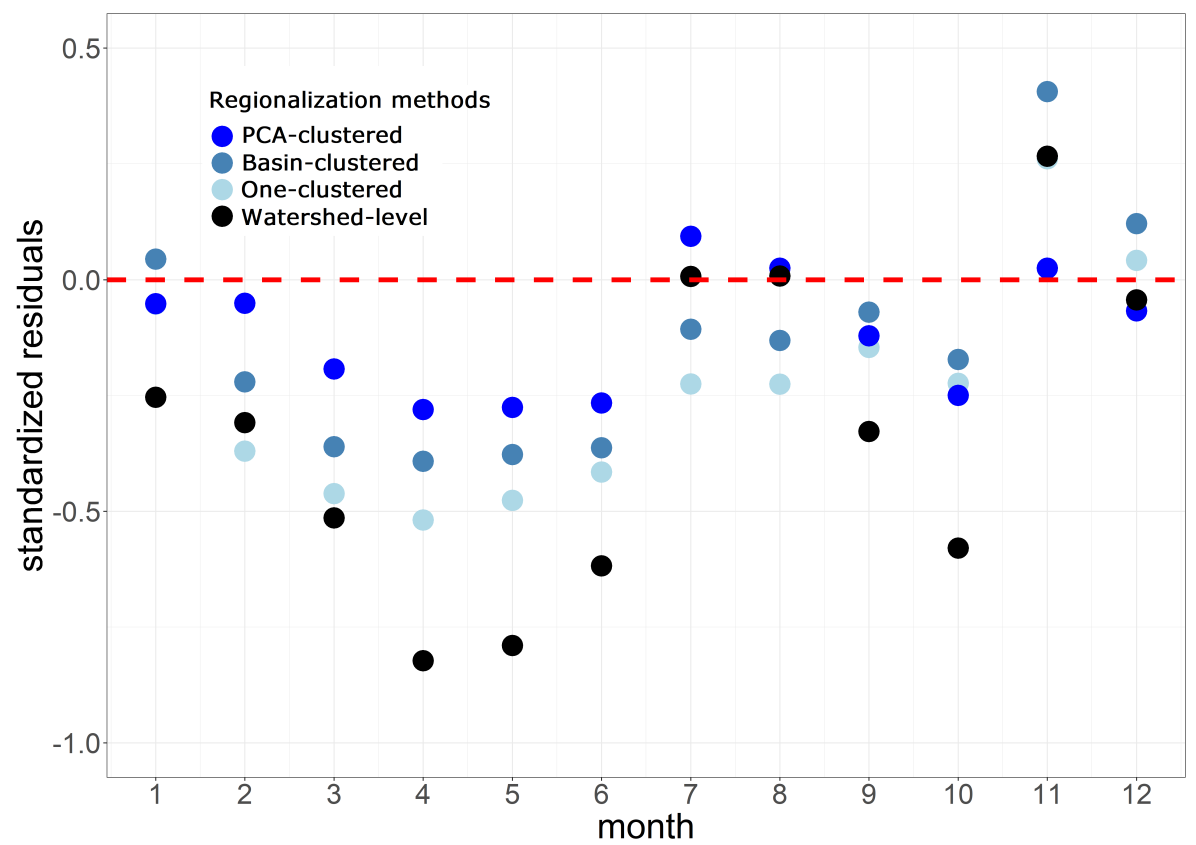

Figure 8. Standardized residuals (observed - predicted) / uncertainty of monthly average flows to show trend of seasonal errors and its magnitude. Below the 0 line depicts that predicted streamflow is overestimated and otherwise if above the line. 


\section{Conclusion}

We explored regionalizing RF models in mountainous watersheds of the Philippines using biophysical, weather, and other watershed data to represent the main inputs of a hydrological system. These datasets were collated as watershed value tables unique per watershed, and followed four grouping schemes namely PCA-clustered, basin-clustered, one-clustered, and watershed-level - all with distinct RF models to be regionalized. The regionalization methods were evaluated using $20 \%$ held-out data of each watershed.

Outcomes of model evaluation amplified that the two-step nature of regionalization (watershed grouping then model transfer) is advisable using our approach. Gains from "outside" watershed information benefited PCA-clustered the most based on goodness-of-fit measures. Results of semi and one-clustered methods suggest that watersheds at major river basin and Luzon scales can be very variable. The watershedlevel with no watershed grouping was the least accurate method, as indicated by the insignificance of static covariates and lesser watershed information. These results suggest to cluster watersheds first prior to streamflow model regionalization, preferably using PCs. That would address gaps from observed data in gauged watersheds and observed data absence in ungauged watersheds.

The PC-based watershed clustering is a biophysical representation where $80 \%$ of the dataset variability is explained by soil, slope, elevation, and land cover. This coincides with the $22 \%$ increase in importance value of physical-static covariates in RF models. On the other hand, covariates weather and month were the most important dynamic covariates, suggesting sensitivity of the RF models to season. The significance of these (mostly open) input data magnifies the increasing momentum on data-driven streamflow modelling. Assuming access to local weather data, our approach can be replicated into other tropical countries. Otherwise, downloadable global weather data can substitute for local data.

Aside from covariates importance, RF (using ranger $\mathrm{R}$ package) accounts for uncertainty and includes it as an RF model output to measure confidence intervals on predicted streamflow. Such output can efficiently identify those significant predicted streamflow. These RF functionalities are recommended to any RF-based streamflow modelling, and also an in-depth sensitivity analysis of covariates and streamflow to assess their causality e.g. use of partial dependence plots.

Uncertainty from predicted streamflow was minimal (lowest CV\%) in watershedlevel method among all methods, while the PCA-clustered had lower CV\% among those with watershed grouping. This suggests a trade-off between additional watershed information and uncertainty. Most uncertain (wide $\mathrm{CI}^{95}$ ) predictions were extreme flows from typhoon events. Such flows were also underestimated and needs improvement for potential flood modelling uses.

Monthly streamflow from several dry and wet months exhibited overestimation evident to all methods - the PCA-clustered having the least overestimation in 8 of 12 months. That prediction bias conforms to events that cause relatively high streamflow even without rainfall e.g. irrigation water supply in dry season, moist soils and recharged aquifers during monsoons, and post-typhoon days in wet season. These ob- 
servations further suggest that the streamflow models can be reactive to seasonal and non-linear realities related to water regulation. Therefore, the regionalization method can be fine-tuned to integrate these water regulation effects (e.g by using more data and covariates, integrate "physics", and switch to deep learning).

Other potential follow-up to this study would be to assess forest loss effect on streamflow and upscale regional PUB nationwide after assigning all ungauged watersheds into clusters. 


\section{Appendix A Standardized residuals per watershed}

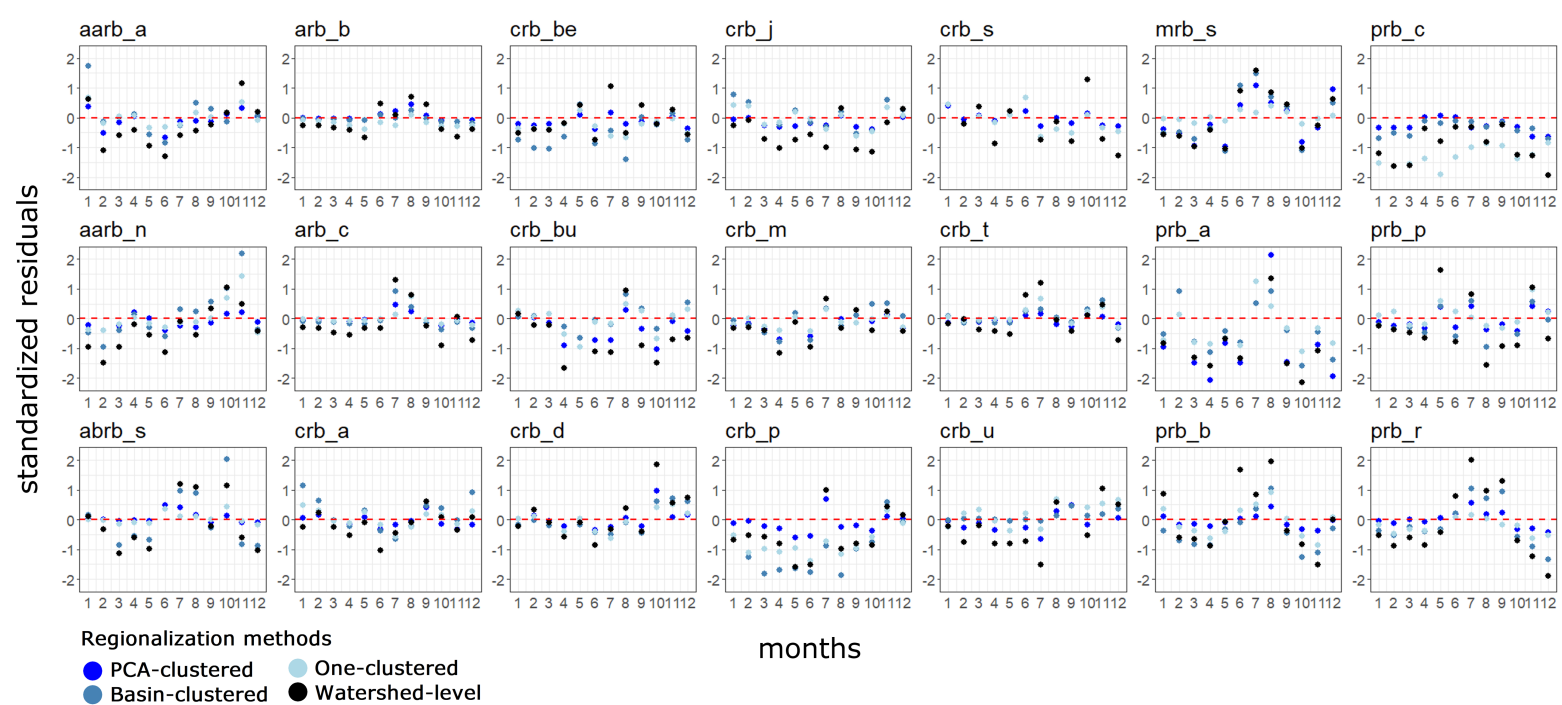

Figure A1. Standardized residuals (observed streamflow - predicted streamflow / uncertainty) per month and per watershed among the four regionalization methods. 


\section{Appendix B Hydrographs of the four regionalization methods}
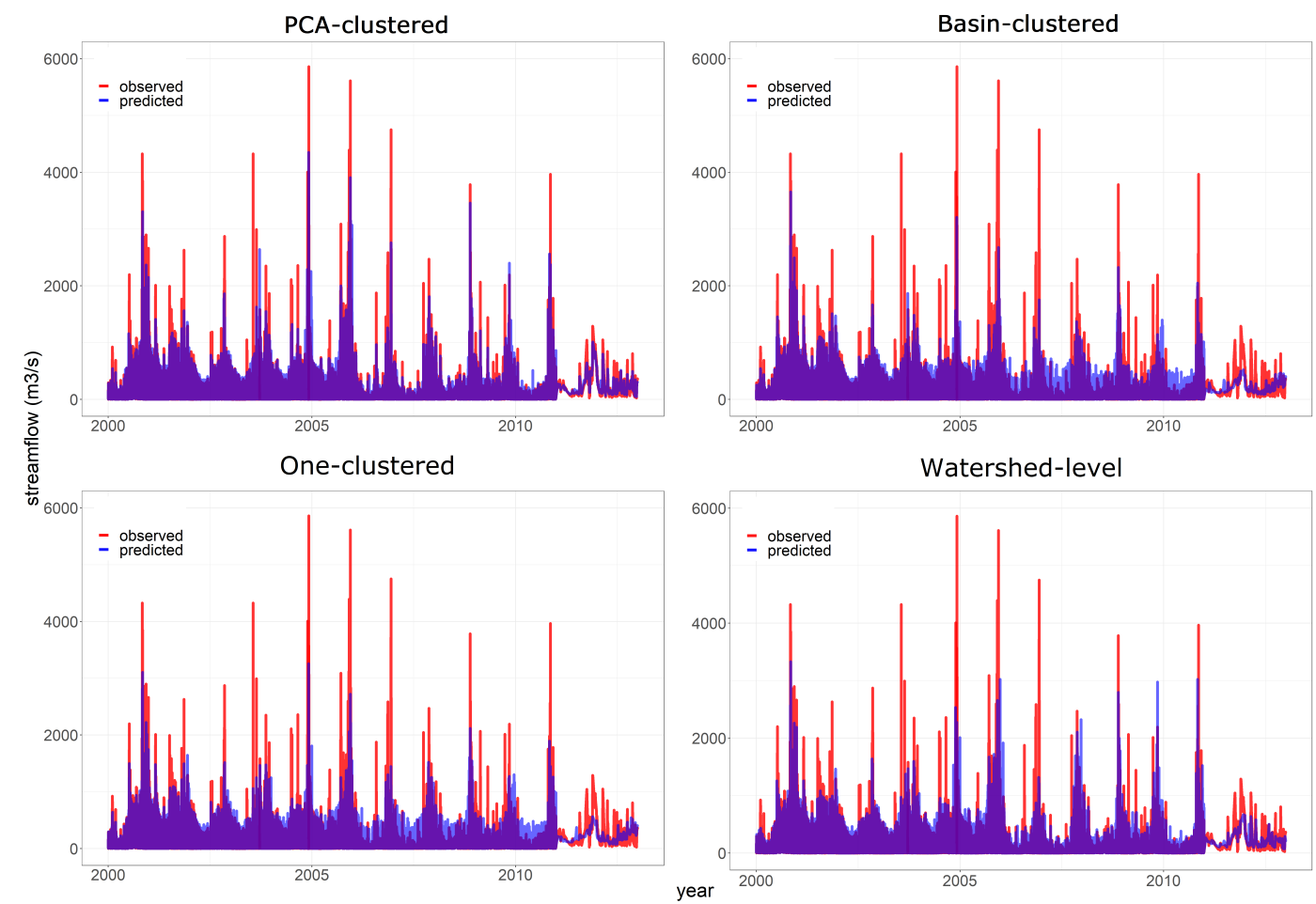

Figure B1. Hydrograph of one-time evaluation showing predicted and observed streamflow, from 2000 to 2016 , for the four regionalization methods.

\section{Acknowledgments}

We give credit to key data sources, PAGASA and DPWH, for providing weather and streamflow data from local stations in the Philippines. Special thanks is given to the Forest Foundation Philippines for providing funds to acquire and pre-process the mentioned data. These data should be accessible at http://bagong.pagasa .dost.gov.ph/for weather and https://apps.dpwh.gov.ph/streams_public/home .aspx for streamflow. Other input data can be accessed online for free as described in the methods section e.g. soil at https://soilgrids.org/\#!/?layer=0RCDRC_M ss12_250m\&vector=1. Codes are accessible at https://github.com/arnanaraza/ streamflow. We declare no conflict of interest on this research.

\section{References}

Abbaspour, K., Vaghefi, S., \& Srinivasan, R. (2017). A guideline for successful calibration and uncertainty analysis for soil and water assessment: A review of papers from the 2016 international SWAT conference. Water, 10(1), 6. Retrieved from https://doi.org/10.3390/w10010006 doi: 10.3390/w10010006

Abdi, H., \& Williams, L. J. (2010). Principal component analysis. Wiley Interdisciplinary Reviews: Computational Statistics, 2(4), 433-459. Retrieved from 
https://doi.org/10.1002/wics.101 doi: 10.1002/wics.101

Altmann, A., Toloşi, L., Sander, O., \& Lengauer, T. (2010). Permutation importance: a corrected feature importance measure. Bioinformatics, 26(10), 13401347. Retrieved from https://doi.org/10.1093/bioinformatics/btq134 doi: 10.1093/bioinformatics/btq134

Arnold, J. G., Moriasi, D. N., Gassman, P. W., Abbaspour, K. C., White, M. J., Srinivasan, R., ... others (2012). SWAT: Model use, calibration, and validation. Transactions of the ASABE, 55(4), 1491-1508. Retrieved from https://doi.org/10.13031/2013.42256 doi: 10.13031/2013.42256

Arsanjani, J. J., Tayyebi, A., \& Vaz, E. (2016). GlobeLand30 as an alternative fine-scale global land cover map: Challenges, possibilities, and implications for developing countries. Habitat International, 55, 25-31. Retrieved from https://doi.org/10.1016/j.habitatint.2016.02.003 doi: 10.1016/j.habitatint.2016.02.003

Arsenault, R., \& Brissette, F. P. (2014). Continuous streamflow prediction in ungauged basins: The effects of equifinality and parameter set selection on uncertainty in regionalization approaches. Water Resources Research, 50(7), 6135-6153. Retrieved from https://doi.org/10.1002/2013wr014898 doi: 10.1002/2013wr014898

Asefa, T., Kemblowski, M., McKee, M., \& Khalil, A. (2006). Multi-time scale stream flow predictions: The support vector machines approach. Journal of Hydrology, 318(1-4), 7-16. Retrieved from https://doi.org/10.1016/j.jhydrol.2005 .06 .001 doi: $10.1016 /$ j.jhydrol.2005.06.001

Athira, P., Sudheer, K. P., Cibin, R., \& Chaubey, I. (2015). Predictions in ungauged basins: an approach for regionalization of hydrological models considering the probability distribution of model parameters. Stochastic Environmental Research and Risk Assessment, 30(4), 1131-1149. Retrieved from https:// doi.org/10.1007/s00477-015-1190-6 doi: 10.1007/s00477-015-1190-6

Beck, H. E., van Dijk, A. I. J. M., de Roo, A., Miralles, D. G., McVicar, T. R., Schellekens, J., \& Bruijnzeel, L. A. (2016). Global-scale regionalization of hydrologic model parameters. $\quad$ Water Resources Research, 52(5), 35993622. Retrieved from https://doi.org/10.1002/2015wr018247 doi: $10.1002 / 2015$ wr018247

Bhattacharyya, S. (2013). Confidence in predictions from random tree ensembles. Knowledge and Information Systems, 35(2), 391-410. Retrieved from https://doi.org/10.1007/s10115-012-0600-z doi: 10.1007/s10115-012-0600-z

Borgonovo, E., Lu, X., Plischke, E., Rakovec, O., \& Hill, M. C. (2017). Making the most out of a hydrological model data set: Sensitivity analyses to open the model black-box. Water Resources Research, 53(9), 7933-7950. Retrieved from https://doi.org/10.1002/2017wr020767 doi: 10.1002/2017wr020767

Boscarello, L., Ravazzani, G., Cislaghi, A., \& Mancini, M. (2016). Regionalization of flow-duration curves through catchment classification with streamflow signatures and physiographic-climate indices. Journal of Hydrologic En- 
gineering, 21(3), 05015027. Retrieved from https://doi.org/10.1061/

(asce)he.1943-5584.0001307 doi: 10.1061/(asce)he.1943-5584.0001307

Breiman, L. (2001).

Machine Learning, 45(1), 5-32. Retrieved from https://doi.org/10.1023/a: 1010933404324 doi: 10.1023/a:1010933404324

Brunner, M. I., Sikorska, A. E., Furrer, R., \& Favre, A.-C. ～(2018). Uncertainty assessment of synthetic design hydrographs for gauged and ungauged catchments. Water Resources Research, 54(3), 1493-1512. Retrieved from https://doi.org/10.1002/2017wr021129 doi: 10.1002/2017wr021129

Chiang, S.-M., Tsay, T.-K., \& Nix, S. J. (2002). Hydrologic regionalization of watersheds. i: Methodology development. Journal of Water Resources Planning and Management, 128(1), 3-11. Retrieved from https://doi.org/10.1061/ (asce) 0733-9496(2002)128:1(3) doi: 10.1061/(asce)0733-9496(2002)128: $1(3)$

Cinco, T., Villafuerte II, M., Ares, E., Manalo, J., Agustin, W., Aquino, K., \& Gaspar, R. (2018). Pagasa, 2018. observed and projected climate change in the philippines, pagasa, quezon city, philippines, 36 pp. PAGASA.

Dias, I., Farinatti, P., De Souza, M., Manhanini, D. P., Balthazar, E., Dantas, D. L., .. Kraemer-Aguiar, L. G. (2015). $\quad$ Effects of resistance training on obese adolescents. $\quad$ Med Sci Sports Exerc, 47(12), 2636-44. Retrieved from https://doi.org/10.1249/mss.0000000000000705 doi: $10.1249 / \mathrm{mss} .0000000000000705$

Do, H. X., Gudmundsson, L., Leonard, M., \& Westra, S. (2018). The global streamflow indices and metadata archive (GSIM) - part 1: The production of a daily streamflow archive and metadata. Earth System Science Data, 10(2), 765785. Retrieved from https://doi.org/10.5194/essd-10-765-2018 doi: 10.5194/essd-10-765-2018

Duku, C., Rathjens, H., Zwart, S. J., \& Hein, L. (2015). Towards ecosystem accounting: a comprehensive approach to modelling multiple hydrological ecosystem services. Hydrology and Earth System Sciences Discussions, 12(3), 34773526. Retrieved from https://doi.org/10.5194/hessd-12-3477-2015 doi: 10.5194/hessd-12-3477-2015

Goswami, M., O’Connor, K., \& Bhattarai, K. (2007). Development of regionalisation procedures using a multi-model approach for flow simulation in an ungauged catchment. Journal of Hydrology, 333(2-4), 517-531. Retrieved from https://doi.org/10.1016/j.jhydrol.2006.09.018 doi: 10.1016/j.jhydrol.2006.09.018

Greacen, E., \& Sands, R. (1980). Compaction of forest soils. a review. Soil Research, 18(2), 163. Retrieved from https://doi.org/10.1071/sr9800163 doi: 10 $.1071 / \operatorname{sr} 9800163$

Greenwell, B. M. (2017). pdp: An r package for constructing partial dependence plots. The $R$ Journal, 9(1), 421-436.

Gupta, H. V., Kling, H., Yilmaz, K. K., \& Martinez, G. F. (2009). Decomposition of the mean squared error and NSE performance criteria: Implications 
for improving hydrological modelling. Journal of Hydrology, 37r(1-2), 80-91. Retrieved from https://doi.org/10.1016/j.jhydrol.2009.08.003 doi: 10.1016/j.jhydrol.2009.08.003

Gupta, H. V., Sorooshian, S., \& Yapo, P. O. (1998). Toward improved calibration of hydrologic models: Multiple and noncommensurable measures of information. Water Resources Research, 34(4), 751-763. Retrieved from https://doi.org/10.1029/97wr03495 doi: 10.1029/97wr03495

Gupta, S. C., \& Larson, W. E. (1979). Estimating soil water retention characteristics from particle size distribution, organic matter percent, and bulk density.

Water Resources Research, 15(6), 1633-1635. Retrieved from https:// doi.org/10.1029/wr015i006p01633 doi: 10.1029/wr015i006p01633

Hamilton, A., \& Moore, R. (2012). Quantifying uncertainty in streamflow records. Canadian Water Resources Journal / Revue canadienne des ressources hydriques, 37(1), 3-21. Retrieved from https://doi.org/10.4296/cwrj3701865 doi: $10.4296 /$ cwrj3701865

Hansen, M. C., Potapov, P. V., Moore, R., Hancher, M., Turubanova, S. A., Tyukavina, A., ... Townshend, J. R. G. (2013). High-resolution global maps of 21st-century forest cover change. Science, 342(6160), 850-853. Retrieved from https://doi.org/10.1126/science.1244693 doi: 10.1126/science.1244693

Hartigan, J. A., \& Wong, M. A. (1979). Algorithm AS 136: A k-means clustering algorithm. Applied Statistics, 28(1), 100. Retrieved from https://doi.org/10 .2307/2346830 doi: 10.2307/2346830

He, Y., Bárdossy, A., \& Zehe, E. (2011). A review of regionalisation for continuous streamflow simulation. Hydrology and Earth System Sciences, 15(11), 35393553. Retrieved from https://doi.org/10.5194/hess-15-3539-2011 doi: 10 .5194/hess-15-3539-2011

Hengl, T., de Jesus, J. M., Heuvelink, G. B. M., Gonzalez, M. R., Kilibarda, M., Blagotić, A., ... Kempen, B. (2017). SoilGrids250m: Global gridded soil information based on machine learning. PLOS ONE, 12(2), e0169748. Retrieved from https://doi.org/10.1371/journal.pone.0169748 doi: 10.1371/journal.pone.0169748

Horner, I., Renard, B., Coz, J. L., Branger, F., McMillan, H. K., \& Pierrefeu, G. (2018). Impact of stage measurement errors on streamflow uncertainty. Water Resources Research, 54(3), 1952-1976. Retrieved from https://doi.org/10.1002/2017wr022039 doi: 10.1002/2017wr022039

Hrachowitz, M., Savenije, H., Blöschl, G., McDonnell, J., Sivapalan, M., Pomeroy, J., ... others (2013). A decade of predictions in ungauged basins (PUB) - a review. Hydrological Sciences Journal, 58(6), 1198-1255. Retrieved from https://doi.org/10.1080/02626667.2013.803183 doi: 10.1080/02626667.2013.803183

Isik, S., \& Singh, V. P. (2008). Hydrologic regionalization of watersheds in turkey. Journal of Hydrologic Engineering, 13(9), 824-834. Retrieved from https://doi.org/10.1061/(asce)1084-0699(2008)13:9(824) doi: 10.1061/(asce)1084-0699(2008)13:9(824) 
Jaranilla-Sanchez, P. A., Wang, L., \& Koike, T. (2011). Modeling the hydrologic responses of the pampanga river basin, philippines: A quantitative approach for identifying droughts. Water Resources Research, 47(3). Retrieved from https://doi.org/10.2208/jscejhe.69.i_13 doi: 10.2208/jscejhe.69.i_13

Jarvis, A., Reuter, H. I., Nelson, A., Guevara, E., et al. (2008). Hole-filled srtm for the globe version 4 available from the CGIAR-CSI SRTM 90m Database (http://srtm. csi. cgiar. org), 15, 25-54.

JICA, N. (1998). Dpwh and republic of the philippines (1998). Water resource management in the Republic of the Philippines-final report Vol. II: Main report.

Kahya, E., Kalayc1, S., \& Piechota, T. C. (2008). Streamflow regionalization: Case study of turkey. Journal of Hydrologic Engineering, 13(4), 205-214. doi: 10 .1061/ASCE1084-0699200813:4205

Latt, Z. Z., Wittenberg, H., \& Urban, B. （2014, October). Clustering hydrological homogeneous regions and neural network based index flood estimation for ungauged catchments: an example of the chindwin river in myanmar. Water Resources Management, 29(3), 913-928. Retrieved from https://doi.org/ 10.1007/s11269-014-0851-4 doi: 10.1007/s11269-014-0851-4

Loukas, A., \& Vasiliades, L. (2014). Streamflow simulation methods for ungauged and poorly gauged watersheds. Natural Hazards and Earth System Sciences, 14 (7), 1641-1661. Retrieved from https://doi.org/10.5194/nhess-14-1641 -2014 doi: 10.5194/nhess-14-1641-2014

Maidment, D. R., \& Morehouse, S. (2002). Arc hydro: Gis for water resources. ESRI, Inc.

Mango, L. M., Melesse, A. M., McClain, M. E., Gann, D., \& Setegn, S. G. (2011). Land use and climate change impacts on the hydrology of the upper mara river basin, kenya: results of a modeling study to support better resource management. Hydrology and Earth System Sciences, 15(7), 2245-2258. Retrieved from https://doi.org/10.5194/hess-15-2245-2011 doi: 10.5194/hess-15-2245-2011

Mohamoud, Y. M. (2008). Prediction of daily flow duration curves and streamflow for ungauged catchments using regional flow duration curves. Hydrological Sciences Journal, 53(4), 706-724. Retrieved from https://doi.org/10.1623/ hysj.53.4.706 doi: 10.1623/hysj.53.4.706

Oki, T. (2006, August). Global hydrological cycles and world water resources. Science, 313(5790), 1068-1072. Retrieved from https://doi.org/10.1126/ science. 1128845 doi: $10.1126 /$ science. 1128845

Oudin, L., Andréassian, V., Perrin, C., Michel, C., \& Moine, N. L. (2008). Spatial proximity, physical similarity, regression and ungaged catchments: A comparison of regionalization approaches based on 913 french catchments. Water Resources Research, 44(3). Retrieved from https://doi.org/10.1029/ 2007wr006240 doi: 10.1029/2007wr006240

Pagliero, L., Bouraoui, F., Diels, J., Willems, P., \& McIntyre, N. (2019). Investigating regionalization techniques for large-scale hydrological modelling. Journal of Hydrology, 570, 220-235. Retrieved from https://doi.org/10.1016/j 
.jhydrol.2018.12.071 doi: 10.1016/j.jhydrol.2018.12.071

Palao, L. K., Dorado, M., Anit, K. P., \& Lasco, R. (2013). Using the soil and water assessment tool (SWAT) to assess material transfer in the layawan watershed, mindanao, philippines and its implications on payment for ecosystem services. Journal of Sustainable Development, 6(6). Retrieved from https://doi.org/10.5539/jsd.v6n6p73 doi: 10.5539/jsd.v6n6p73

Papacharalampous, G. A., \& Tyralis, H. (2018). Evaluation of random forests and prophet for daily streamflow forecasting. Advances in Geosciences, 45, 201208. Retrieved from https://doi.org/10.5194/adgeo-45-201-2018 doi: 10 $.5194 /$ adgeo-45-201-2018

Penman, H. L. (1948). Natural evaporation from open water, bare soil and grass. Proceedings of the Royal Society of London. Series A. Mathematical and Physical Sciences, 193(1032), 120-145. Retrieved from https://doi.org/10.1098/ rspa.1948.0037 doi: 10.1098/rspa.1948.0037

Prieto, C., Vine, N. L., Kavetski, D., García, E., \& Medina, R. (2019). Flow prediction in ungauged catchments using probabilistic random forests regionalization and new statistical adequacy tests. Water Resources Research. Retrieved from https://doi.org/10.1029/2018wr023254 doi: 10.1029/2018wr023254

Probst, P., Wright, M. N., \& Boulesteix, A.-L. (2019). Hyperparameters and tuning strategies for random forest. Wiley Interdisciplinary Reviews: Data Mining and Knowledge Discovery, 9(3). Retrieved from https://doi.org/10.1002/widm .1301 doi: 10.1002/widm.1301

Pryde, J. K., Osorio, J., Wolfe, M., Heatwole, C., Benham, B., \& Cardenas, A.

(2007). Comparison of watershed boundaries derived from srtm and aster digital elevation datasets and from a digitized topographic map.

R Core Team. (2013). R: A language and environment for statistical computing [Computer software manual]. Vienna, Austria. Retrieved from http://www.R -project.org/

Rawlins, M. A., Aggabao, F., Calderon, M., Jerbelle Elomina, Ignacio, G. B., \& Arnan Araza. (2016). Understanding the role of forests in supporting livelihoods and climate resilience case studies in the philippines. Retrieved from http://rgdoi.net/10.13140/RG.2.2.32598.19522 doi: 10.13140/RG.2.2.32598.19522

Razavi, T., \& Coulibaly, P. (2013). Classification of ontario watersheds based on physical attributes and streamflow series. Journal of Hydrology, 493, 81-94. Retrieved from https://doi.org/10.1016/j.jhydrol.2013.04.013 doi: 10.1016/j.jhydrol.2013.04.013

Reynolds, L. V., \& Shafroth, P. B. (2016). Modeled streamflow metrics on small, ungaged stream reaches in the upper colorado river basin. US Geological Survey. Retrieved from https://doi.org/10.3133/ds974 doi: 10.3133/ds974

Rousseeuw, P. J. (1987). Silhouettes: A graphical aid to the interpretation and validation of cluster analysis. Journal of Computational and Applied Mathematics, 20,53-65. Retrieved from https://doi.org/10.1016/0377-0427(87)90125 -7 doi: 10.1016/0377-0427(87)90125-7 
Saadi, M., Oudin, L., \& Ribstein, P. (2019). Random forest ability in regionalizing hourly hydrological model parameters. Water, 11(8), 1540. Retrieved from https://doi.org/10.3390/w11081540 doi: 10.3390/w11081540

Senent-Aparicio, J., Jimeno-Sáez, P., Bueno-Crespo, A., Pérez-Sánchez, J., \& Pulido-Velázquez, D. (2019). Coupling machine-learning techniques with SWAT model for instantaneous peak flow prediction. Biosystems Engineering, 177, 67-77. Retrieved from https://doi.org/10.1016/ j.biosystemseng. 2018.04.022 doi: 10.1016/j.biosystemseng.2018.04.022

Shortridge, J. E., Guikema, S. D., \& Zaitchik, B. F. (2016). Machine learning methods for empirical streamflow simulation: a comparison of model accuracy, interpretability, and uncertainty in seasonal watersheds. Hydrology and Earth System Sciences, 20(7), 2611-2628. Retrieved from https://doi.org/ 10.5194/hess-20-2611-2016 doi: 10.5194/hess-20-2611-2016

Singh, V. P. (1997). Effect of spatial and temporal variability in rainfall and watershed characteristics on stream flow hydrograph. Hydrological Processes, 11(12), 1649-1669. Retrieved from https://doi.org/10.1002/ (sici) 1099-1085(19971015) $11: 12<1649:$ : aid-hyp495>3.0.co;2-1 doi: 10.1002/(sici)1099-1085(19971015)11:12〈1649::aid-hyp495〉3.0.co;2-1

Solomatine, D. P., \& Ostfeld, A. (2008). Data-driven modelling: some past experiences and new approaches. Journal of Hydroinformatics, 10(1), 3-22. Retrieved from https://doi.org/10.2166/hydro.2008.015 doi: 10.2166/hydro .2008 .015

Tian, Y., Booij, M. J., \& Xu, Y.-P. (2013). Uncertainty in high and low flows due to model structure and parameter errors. Stochastic Environmental Research and Risk Assessment, 28(2), 319-332. Retrieved from https://doi.org/10.1007/ s00477-013-0751-9 doi: 10.1007/s00477-013-0751-9

Tigkas, D., Vangelis, H., \& Tsakiris, G. (2012). Drought and climatic change impact on streamflow in small watersheds. Science of The Total Environment, 440, 33-41. Retrieved from https://doi.org/10.1016/j.scitotenv.2012.08.035 doi: $10.1016 /$ j.scitotenv.2012.08.035

Tuddao Jr, V. B. (2009). Framework planning for basin-level management-the philippine approach. Center for River Basin Organizations and Management (CRBOM)'s, Small Publication Series(12).

Tyralis, H., Papacharalampous, G., \& Langousis, A. (2019). A brief review of random forests for water scientists and practitioners and their recent history in water resources. Water, 11(5), 910. Retrieved from https://doi.org/ 10.3390/w11050910 doi: 10.3390/w11050910

Wager, S., Hastie, T., \& Efron, B. (2014). C Confidence intervals for random forests: The jackknife and the infinitesimal jackknife. The Journal of Machine Learning Research, 15(1), 1625-1651.

Warmerdam, F. (2008). The geospatial data abstraction library. In Open source approaches in spatial data handling (pp. 87-104). Springer Berlin Heidelberg. Retrieved from https://doi.org/10.1007/978-3-540-74831-1_5 doi: 10.1007/ 978-3-540-74831-1_5 
Winiger, M., Gumpert, M., \& Yamout, H. (2005). Karakorum-hindukush-western himalaya: assessing high-altitude water resources. Hydrological Processes, 19(12), 2329-2338. Retrieved from https://doi.org/10.1002/hyp.5887 doi: $10.1002 /$ hyp. 5887

Wohl, E., Barros, A., Brunsell, N., Chappell, N. A., Coe, M., Giambelluca, T., ... Ogden, F. (2012). The hydrology of the humid tropics. Nature Climate Change, 2(9), 655-662. Retrieved from https://doi.org/10.1038/ nclimate1556 doi: 10.1038/nclimate1556

Wright, M. N., \& Ziegler, A. (2017). ranger: A fast implementation of random forests for high dimensional data in c and r. Journal of Statistical Software, 77(1). Retrieved from https://doi.org/10.18637/jss.v077.i01 doi: 10.18637/jss.v077.i01

Wu, C., Chau, K., \& Fan, C. (2010). Prediction of rainfall time series using modular artificial neural networks coupled with data-preprocessing techniques. Journal of Hydrology, 389(1-2), 146-167. Retrieved from https://doi.org/10.1016/j .jhydrol.2010.05.040 doi: 10.1016/j.jhydrol.2010.05.040

Yadav, M., Wagener, T., \& Gupta, H. (2007). Regionalization of constraints on expected watershed response behavior for improved predictions in ungauged basins. $\quad$ Advances in Water Resources, 30(8), 1756-1774. Retrieved from https://doi.org/10.1016/j.advwatres.2007.01.005 doi: 10.1016/j.advwatres.2007.01.005

Yang, R.-M., Zhang, G.-L., Liu, F., Lu, Y.-Y., Yang, F., Yang, F., .. L Li, D.-C.

(2016). Comparison of boosted regression tree and random forest models for mapping topsoil organic carbon concentration in an alpine ecosystem. Ecological Indicators, 60, 870-878. Retrieved from https://doi.org/10.1016/ j.ecolind.2015.08.036 doi: 10.1016/j.ecolind.2015.08.036

Zhang, G., \& Lu, Y. (2012). Bias-corrected random forests in regression. Journal of Applied Statistics, 39(1), 151-160. Retrieved from https://doi.org/10 .1080/02664763.2011.578621 doi: 10.1080/02664763.2011.578621 